\title{
Evaluating the environmental profiles of winter wheat rotation systems under different management strategies
}

\author{
Sara González-García a,b,*, Fernando Almeida ${ }^{\mathrm{c}, \mathrm{d}}$, Maria Teresa Moreira ${ }^{\mathrm{a}}$, Miguel Brandão ${ }^{\mathrm{b}}$ \\ a CRETUS Institute, Department of Chemical Engineering, School of Engineering, University of Santiago de Compostela, 15782 Santiago de Compostela, Spain \\ ${ }^{\mathrm{b}}$ Department of Sustainable Development, Environmental Science and Engineering (SEED), KTH - Royal Institute of Technology, Stockholm, Sweden \\ c Grupo Da Cunha, 15175 Carral, Spain \\ d Department of Analytical Chemistry, Faculty of Sciences, Universidade de Santiago de Compostela, 27002 Lugo, Spain
}

\section{H I G H L I G H T S}

- Nine wheat rotations with alternate crops (potato, maize and rapeseed) were assessed.

- The best land management systems per hectare and $€$ were identified.

- Arable operations are critical contributors to the environmental profile.

- Carbon storage in the soil when returning straw involves environmental credits.

- Results are quite sensitive to the delimitation of the system boundary.

\section{A R T I C L E I N F O}

\section{Article history:}

Received 9 December 2020

Received in revised form 13 January 2021

Accepted 14 January 2021

Available online 21 January 2021

Editor: Damia Barcelo

\section{Keywords:}

Attributional LCA

Bread

Crop rotation

Integrated assessment

Maize

Potato

Oilseed rape
G R A P H I C A L A B S T R A C T

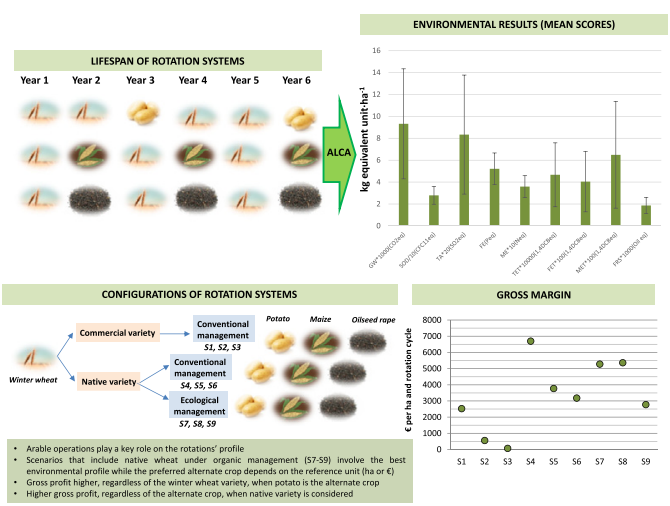

\begin{abstract}
A B S T R A C T
Climate change poses a remarkable challenge to global food security, for which wheat is one of the main staple agricultural commodities. The cultivation of different varieties of winter wheat in Galicia (commercial and native) under rotation systems with potato, maize and oilseed rape was evaluated from an environmental point of view. The general approach of this study included the gathering of the inventory data of the different crops, the quantification of their environmental impacts and economic benefits, to identify the best land management system. Life Cycle Assessment (LCA) was used as environmental tool. The environmental profiles of each rotation system were reported in terms of nine impact categories. Crop rotations were analysed both per hectare and per $€$ of gross margin, so that the information can be relevant to land-management decisions. Preference ranks were established based on an environmental normalized score for both units. The results suggest that arable operations contribute decisively to the environmental profile of the rotations. The avoided mineral fertilization processes, the carbon storage in the soil when returning straw to the field, as well as the electricity production clearly influence the environmental impact of the rotations. Scenarios that include native wheat under organic management are always the environmentally preferred ones while the preferred alternate crop depends on the reference unit. Concerning the margin gross, scenarios including the native variety report the highest profits, being the potato the preferred alternate crop. Further assessment needs to be undertaken to identify differences in the results of different ways of conducting LCA, i.e. attributional vs consequential approaches.

(C) 2021 The Authors. Published by Elsevier B.V. This is an open access article under the CC BY-NC-ND license (http:// creativecommons.org/licenses/by-nc-nd/4.0/).
\end{abstract}

\footnotetext{
* Corresponding author at: CRETUS Institute, Department of Chemical Engineering, School of Engineering, University of Santiago de Compostela, 15782 Santiago de Compostela, Spain. E-mail address: sara.gonzalez@usc.es (S. González-García).
} 


\section{Introduction}

Climate change is already having profound consequences on biodiversity because of the increase of carbon emissions. The adverse impacts of climate change represent a potentially considerable challenge to global food security (Mäkinen et al., 2018; Li et al., 2020). In this regard, agriculture is arguably the sector most affected by climate change. The relationship between climate change and crop production depends largely on when and what mitigation and adaptation actions are adopted.

Cereal grains and tubers are the most common food staples. The world produces about two billion tonnes of cereals annually for human food or livestock feed (Oteros et al., 2015). Cereals provide high levels of carbohydrates, dietary fibre and protein. Among cereals, wheat is the most widely cultivated plant in the world (Le Gouis et al., 2020; Campo de Tejada, 2020) and is considered a key crop in the context of food security (Erice et al., 2019). More than 200 Mha in the world are dedicated to wheat cultivation due to its significant commercial importance (pasta, couscous, bread and bulgur are wheat products) (Câmara-Salim et al., 2020). In addition, wheat grain and its products provide $18 \%$ of the food calories ingested by the world population (Erice et al., 2019). In 2018, this crop constituted $43 \%$ of the cereal produced in the EU (Eurostat, 2020), which is the largest producer in the world (Xynias et al., 2020). Spain is a major producer of cereals (24.5 Mt and 6 Mha in cereal production in 2018), where wheat and barley are the most produced (SAAFFM, 2018).

There are several types of wheat, the most cultivated being common wheat (Triticum aestivum L., ssp. aestivum) and durum wheat (Triticum turgidum ssp. durum Desf.). Common wheat is mainly used to produce flour for bread due to its higher fermentation capacity. On the contrary, durum wheat is dedicated to pasta production due to its higher protein content. The production of common wheat in Spain is much higher than that of durum wheat, which is grown mainly in other Mediterranean countries such as Italy. The average annual production of Spain is 12 Mt for the former and $1 \mathrm{Mt}$ for the latter (Campo de Tejada, 2020).

The quality of wheat depends not only on the variety used but also on its ability to accumulate protein reserves in the grain, which is determined by nitrogen fertilization (Hellemans et al., 2018). It is therefore necessary to pay special attention to effective fertilization protocols, mainly in humid Mediterranean areas (Blandino et al., 2020). In many countries, intensive crop production has depleted soil fertility, jeopardizing its long-term productive capacity and consequently its ability to meet the needs of future generations. Intensification has led to many environmental issues, such as high consumption of non-renewable energy resources, loss of biodiversity and pollution of the aquatic environment by leaching. Mineral fertilizers are the main source of nutrients, although the contribution of animal manure remains significant in areas where livestock are present. More than $50 \%$ of the nitrogen applied to the soil is not used by the crop plant and may be taken up by the soil microbiome (Liu et al., 2016). Nitrogen is directly lost as nitrous oxide $\left(\mathrm{N}_{2} \mathrm{O}\right)$ and through volatilization (ammonia, $\mathrm{NH}_{3}$ and nitrogen oxides, $\mathrm{NO}_{\mathrm{x}}$ ) or leaching (nitrate, $\mathrm{NO}_{3}^{-}$) (Pan, 2016; Liu et al., 2016; Wowra et al., 2020). The loss of nitrogen in its different forms can have a detrimental impact on living organisms (Habermeyer et al., 2015) and has a negative effect on the environment by causing eutrophication of freshwater and marine ecosystems (Nemecek et al., 2015) gas and global warming (Nemecek et al., 2011a; Goglio et al., 2012), among others. Therefore, nitrogen management is shown to be a key driver of the environmental impacts of agricultural systems.

Reducing environmental impacts from agriculture requires an understanding of how alternative agricultural production systems and the efficiency of agricultural inputs drive environmental degradation. Sustainable production relies on an integrated agriculture that optimizes nutrient and pest-and-disease protection through integrated nutrient and pest management. In this context, crop rotation, aligned with practices that enhance the activity of beneficial soil microorganisms, can regulate the biogeochemical soil cycles and affecting soil fertility (Watts-Williams and Cavagnaro, 2018; Mäkinen et al., 2018; Hendrickson and Colazo, 2019). Crop rotation consists of growing different crops (cereals, root crops, rapeseed, legumes) in sequence on a field in 4-6 year cycles that also include cover/catch crops. According to Ghaley et al. (2018), crop rotation reports the greatest positive effect on biomass yields and, nutrient retention and cycling in comparison with monoculture.

The design of environmentally efficient crop rotations requires a comprehensive tool that allows the assessment of the different environmental impacts caused directly by the cropping systems, as well as those arising because of the inputs used. The Life Cycle Assessment (LCA) methodology has been widely applied to quantify and compare the environmental impacts of agricultural systems (González-García et al., 2013, 2016; Nemecek et al., 2011b, 2015; Noya et al., 2015, 2017; Pishgar-Komleh et al., 2019; Salim et al., 2019). This methodology aims at identifying possible reductions of environmental impacts by identifying improvements in the systems analysed. Moreover, by accounting for different life cycle phases, shifts in environmental burdens between life cycle stages can be avoided. The cultivation of different varieties of winter wheat in Galicia (NW Spain) under rotation systems with potato, maize and oilseed rape was environmentally analysed in this study. The interest in the cultivation of wheat in this Spanish region is due to the fact that its production is expected to double in the next few years due to the Protected Geographical Indication ${ }^{1}$ granted to Galician bread as a quality reference at national level. This bread presents a distinct flavour and taste due to its differentiated production scheme, based on the use of sourdough and the requirement for longer fermentation times and baking in stone ovens (CâmaraSalim et al., 2020). The general approach consisted in gathering the inventory data of the different crops, which allowed for the quantification of their environmental effect, as well as identifying the environmental hotspots. For the first time, such different crop rotation systems based on wheat have been analysed from both environmental and economic perspectives. Finally, the most favourable land management system will be identified, being the one that reports the greatest economic revenue and the least environmental impact, considering that rotation systems give rise to different co-products (wheat grain, wheat straw, tubers, maize silage and oilseeds).

\section{Materials and methods}

In this study, LCA methodology was used to evaluate the environmental impacts of different cropping systems under rotation regimes to produce winter wheat grain for bread. The international standards ISO 14040 (ISO, 2006a) and 14044 (ISO, 2006b) were followed in detail. Different ways of performing LCA can be used to assess the environmental profiles of product systems, i.e., attributional or consequential, and LCA results are highly dependent on the LCA approach taken, which determines the delimitation of the system boundaries. In Attributional LCA (ALCA), all inputs and outputs of a production system are attributed to the functional unit by linking and/or partitioning the unit processes of the system according to a normative rule (e.g., allocation factors based on economic, mass or energy values, among others). In Consequential LCA (CLCA), all activities in a production system are linked so that they are included in the production system to the extent that they are expected to change because of a change in demand for the functional unit (Ekvall, 2020). There is a strong connection between the selected methodological approach and the way co-products are handled in multi-output activities. Since average data were available and the focus of this study was really to describe the environmentally relevant physical flows within a time window, but not to describe how environmentally relevant flows will change in the future in response to possible decisions, the ALCA methodology was adapted.

\footnotetext{
1 https://www.mapa.gob.es/es/alimentacion/temas/calidad-diferenciada/ publicsolicitregistroydudouec2433de19072019_tcm30-524594.pdf.
} 


\subsection{Goal and scope definition}

The main goal of this study was to perform a comprehensive environmental and economic analysis of the different cropping systems destined mainly to the production of winter wheat (Triticum aestivum L.) and considering three different crop rotations. Regarding wheat crops, two varieties were considered: commercial and autochthonous (Galician). Commercial winter wheat under conventional management (C-WW), Galician winter wheat ("trigo del país", Caaveiro variety) under conventional management (GcWW) and Galician winter wheat under ecological management $(\mathrm{Ge}-\mathrm{WW})$ in three different six-year rotation cycles were considered. The crops evaluated were winter wheat with maize (Zea mays L.), winter wheat with oilseed rape or rapeseed (Brassica napus L.) and winter wheat with potato (Solanum tuberosum L.).

Cropping systems were arranged in 40 ha plots per whole rotation located in Galicia (NW Spain), covering an area of 450 ha and correspond to 51 farmers. The regions under analysis (Carral, Laracha and Xinxo) represent a population of around 27,000 inhabitants and $300 \mathrm{~km}^{2}$ of surface area. The nine scenarios differed in terms of soil tillage, use of agrochemicals (including mineral and organic fertilizers and other agrochemicals such as herbicides, fungicides and insecticides), biomass yields and economic revenue. Table 1 details the nine 6-year crop rotation cycles based on winter wheat (C-WW, Gc-WW and Ge-WW) with potato (P), maize (M) or oilseed rape (OSR) as co-products. The croplands under study were dedicated to agriculture in the last 20 years, producing arable crops, mainly wheat. The experimental plots were set in regions where the climate is oceanic with coastal, Mediterranean, inland and mountain variants. The average annual precipitation in the area is $750-1000 \mathrm{~mm}$, concentrated mainly in autumn and winter. Regarding the soil, the clay content is $4.9 \%, \mathrm{pH}$ is 5 and the soil organic carbon (SOC) content is around $55 \mathrm{tC} \cdot \mathrm{ha}^{-1}$ in the upper $30 \mathrm{~cm}$.

As for the scope of the study, it was conducted from a cradle-to-farm gate perspective. For each crop rotation system, the system included the production of all inputs, such as machinery, agrochemicals, seeds and diesel, as well as their use (i.e., the operation of machinery in the field) and the corresponding direct emissions (i.e., combustion emissions from diesel use and direct field emissions from agrochemicals application). Regarding the system boundaries for each rotation system, the rotation began after the harvest of the previous crop and ended with the harvest of the last crop (rotations of 6 years). Furthermore, hotspots identification was performed, which implies the identification of the elements or activities within the agricultural systems that contribute most to a certain impact category.

Table 1

Crop rotation cycles of 6 years under study $\left(\mathrm{S}_{\mathrm{i}}\right)$ and main yields. C-WW: Commercial winter wheat; Gc-WW: Galician winter wheat (native variety) - conventional management; Ge-WW: Galician winter wheat (native variety) - ecological management; P: Potato; M: Maize; OSR: Oilseed rape.

\begin{tabular}{|c|c|c|c|c|c|c|c|c|c|c|}
\hline & & & \multicolumn{2}{|c|}{ Year } & \multicolumn{4}{|c|}{ Main crop (WW) } & \multicolumn{2}{|c|}{$\begin{array}{c}\text { Alternate } \\
\text { crop }\end{array}$} \\
\hline Scenario & 1 & 2 & 3 & 4 & 5 & 6 & $\begin{array}{c}\text { t } \\
\operatorname{grain} \cdot h^{-1}\end{array}$ & t straw $\cdot h^{-1}$ & $\mathbf{t} \cdot \mathbf{h a} \mathbf{a}^{-1}$ & $\begin{array}{c}€ \cdot \\
\text { ha }^{-1}\end{array}$ \\
\hline S1 & $\begin{array}{c}\text { C- } \\
\text { WW1 }\end{array}$ & $\begin{array}{c}\text { C- } \\
\text { WW2 }\end{array}$ & P1 & $\begin{array}{c}\text { C- } \\
\text { WW1 }\end{array}$ & $\begin{array}{c}\text { C- } \\
\text { WW2 }\end{array}$ & P1 & 22.00 & 7.48 & 70 & 15,354 \\
\hline S2 & $\begin{array}{c}\text { C- } \\
\text { WW3 }\end{array}$ & M1 & $\begin{array}{c}\text { C- } \\
\text { WW3 }\end{array}$ & M1 & $\begin{array}{c}\text { C- } \\
\text { WW3 }\end{array}$ & M1 & 15.60 & 5.30 & 90 & 8891 \\
\hline S3 & $\begin{array}{c}\text { C- } \\
\text { WW4 }\end{array}$ & OSR1 & $\begin{array}{c}\text { C- } \\
\text { WW4 }\end{array}$ & OSR1 & $\begin{array}{c}\text { C- } \\
\text { WW4 }\end{array}$ & OSR1 & 15.00 & 5.10 & 10.50 & 6507 \\
\hline S4 & $\begin{array}{c}\text { Gc- } \\
\text { WW1 }\end{array}$ & $\begin{array}{c}\text { Gc- } \\
\text { WW2 }\end{array}$ & $\mathbf{P 2}$ & $\begin{array}{c}\text { Gc- } \\
\text { WW1 }\end{array}$ & $\begin{array}{c}\text { Gc- } \\
\text { WW2 }\end{array}$ & P2 & 11.20 & - & 70 & 14,910 \\
\hline S5 & $\begin{array}{c}\text { Gc- } \\
\text { WW3 }\end{array}$ & M2 & $\begin{array}{c}\text { Gc- } \\
\text { WW3 }\end{array}$ & M2 & $\begin{array}{c}\text { Gc- } \\
\text { WW3 }\end{array}$ & M2 & 8.10 & - & 90 & 8640 \\
\hline S6 & $\begin{array}{c}\text { Gc- } \\
\text { WW4 }\end{array}$ & OSR2 & $\begin{array}{c}\text { Gc- } \\
\text { WW4 }\end{array}$ & OSR2 & $\begin{array}{c}\text { Gc- } \\
\text { WW4 }\end{array}$ & OSR2 & 7.50 & - & 10.50 & 6150 \\
\hline S7 & $\begin{array}{c}\text { Ge- } \\
\text { WW1 }\end{array}$ & $\begin{array}{c}\text { Ge- } \\
\text { WW2 }\end{array}$ & P3 & $\begin{array}{c}\text { Ge- } \\
\text { WW1 }\end{array}$ & $\begin{array}{c}\text { Ge- } \\
\text { WW2 }\end{array}$ & P3 & 10,00 & - & 40 & 14,900 \\
\hline S8 & $\begin{array}{c}\text { Ge- } \\
\text { WW3 }\end{array}$ & M3 & $\begin{array}{c}\text { Ge- } \\
\text { WW3 }\end{array}$ & M3 & $\begin{array}{c}\text { Ge- } \\
\text { WW3 }\end{array}$ & M3 & 6.60 & - & 75 & 9918 \\
\hline S9 & $\begin{array}{c}\text { Ge- } \\
\text { WW4 }\end{array}$ & OSR3 & $\begin{array}{c}\text { Ge- } \\
\text { WW4 }\end{array}$ & OSR3 & $\begin{array}{c}\text { Ge- } \\
\text { WW4 }\end{array}$ & OSR3 & 6.00 & - & 7.50 & 5880 \\
\hline
\end{tabular}

Yellow color - wheat; Orange color - Maize; Green color - Potato; Blue color - Oilseed rape. 


\subsection{Functional unit and allocation}

It is important to consider the multifunctionality of each agricultural system under study, which requires an analysis that considers alternative functional units. The main goal for the farmers, and thus the function of this study, is to maximize the production of wheat grain. Nevertheless, each cropping system yields additional products (straw, potatoes, maize silage or rapeseed) with industrial or agricultural uses and thereby provides an additional economic benefit. According to the literature (e.g. Deytieux et al., 2012; Nemecek et al., 2011a, 2011b; Goglio et al., 2012; Pishgar-Komleh et al., 2019), the results and thus, the decision supported by farmers and consumers differs considerably when expressed as a land-based unit, a biomass-based unit or an economic based unit.

Therefore, in this study the hectare of land (ha) was used as base functional unit. This unit gives farmers an idea of how to manage their land to minimize environmental impacts. It also provides an answer to the question: What is the best use of land from an environmental perspective, regardless of the crops grown or revenue obtained?

In addition, the discussion of the results incorporated the profiles of each rotation system in terms of gross margin. The gross margin is estimated by discounting the total production costs (including costs of activities and inputs) to the total income from the sales of products. This reference unit gives an idea of the environmental burdens on the economic revenue from agricultural activities. Therefore, in this case, the goal is to minimize the impact per $€$. This unit gives an answer to the question: What is the rotation system that produces the greatest economic benefit for the farmer with the least environmental impact? Since the comparison is made at the crop-rotation level, no allocation is needed.

\subsection{Description of the cropping systems under assessment}

The agricultural systems analysed are dedicated to the production of winter wheat considering the two varieties mentioned: commercial and native. Both varieties are different not only in terms of production capacity and agrochemical requirements, but also in terms of chemical composition. In this regard, the native variety reports a higher protein content and a lower starch content than the commercial variety. Crop rotations with potato, maize and oilseed rape are considered. As a result, nine crop rotation scenarios were designed. The set of crop rotations included those typically practiced in the region (e.g., maize and potatoes), but also new crop rotations that are rarely practiced, but that have potential to be incorporated, such as oilseed rape. As a result, a total of 9 crop combinations were considered: S1: (C-WW1 + C-WW2 + P1) X2; S2: (C-WW3 + M1)x3; S3: (C-WW4 + OSR1)x3; S4: $($ Gc-WW1 + Gc-WW2 + P)x2; S5: (Gc-WW3 + M2)x3; S6: $($ Gc-WW4 + OSR2)x3; S7: (Ge-WW1 + Ge-WW2 + P3)x2; S8: (Ge-WW3 + M3)x3; S9: (Ge-WW4 + OSR3)x3 as shown in Table 1.

Regardless of the varieties, the activities performed for each crop were classified into three main stages, which are field establishment, crop growth and biomass harvesting. All these stages included different processes which have been identified in detail for each crop. To do so, specific questionnaires were designed to identify not only the operations and machinery involved but also the demand of inputs from farmers. Agricultural activities start with the field establishment stage, where the soil is prepared for sowing. Crop-growth related activities include the application of fertilizers and other agrochemicals (i.e., pesticides, insecticides, fungicides), and mechanical treatment. Finally, the biomass-harvesting stage includes harvesting and additional activities, such as baling and transport to storage in silos, if necessary.

To delimit the activities for a specific crop in a rotation system, the interval considered for each crop started after the harvest of the preceding crop and ended with the harvest of the main crop. Therefore, any period between the harvesting of a crop and soil tillage activities of the next crop was attributed to the latter. Nevertheless, it is important to note that there are some gaps in LCA methodology applied to agricultural systems specifically in crop rotation systems, since there are some interactions between the individual crops of the rotation that could be neglected if the crops are assessed individually.

\subsubsection{Winter wheat cropping systems}

2.3.1.1. Commercial winter wheat cultivation ( $C-W W$ ). The cultivation of the commercial variety starts with mouldboard ploughing before the application of a complex mineral fertilizer ( $8 \mathrm{~N}-15 \mathrm{P}-15 \mathrm{~K})$. Secondly, the soil is tilled, and seeds are sown $\left(200 \mathrm{~kg} \cdot \mathrm{ha}^{-1}\right)$ in November. During crop growth, there are four applications of agrochemicals: chlortoluron and diflufenican (pre-emergence herbicide treatment), tribenuronmethyl and pinoxaden (post-emergence herbicide treatment), calcium ammonium nitrate (mineral fertilization) and tebuconazole (fungicide treatment). Finally, biomass is harvested in August. The grain is separated from the straw. While $15 \%$ of the latter is left in the field, the remaining $85 \%$ is sold for bedding and cattle feed, so a baling process is required.

\subsubsection{Cultivation of native Galician winter wheat in conventional regime} $(G c-W W)$. The cultivation of the Galician variety under conventional conditions is less intensive in terms of agrochemical requirements and agricultural activities. Field establishment requires mouldboard ploughing and milling before sowing ( $150 \mathrm{~kg}$ seeds $\cdot \mathrm{ha}^{-1}$ ) in November. After sowing and before the harvest, three agrochemicals are applied: herbicide (chlortoluron and diflufenican), mineral fertilizer (calcium ammonium nitrate) and fungicide (tebuconazole). In this crop, all the wheat straw is left in the field as nutrients supplier for the next crop in the rotation system.

2.3.1.3. Cultivation of native Galician winter wheat in organic regime (Ge-WW). Following the principles of organic agriculture, cultivation is aimed at minimizing the use of inputs and there is a strict limitation on the use of synthetic pesticides and mineral fertilizers. Thus, the use of mineral fertilizers, herbicides, fungicides or insecticides has not been considered in the cultivation of the Galician variety under the organic regime. The field is prepared before sowing by chisel ploughing (more superficial than mouldboard ploughing) and organic fertilization is carried out with poultry manure (supplied by ecological farms). Sowing ( $150 \mathrm{~kg}$ seeds $\left.\cdot \mathrm{ha}^{-1}\right)$ is combined with soil tillage. Before harvesting (also in November), two treatments are performed: the first one is a mechanical treatment to remove weeds, since there is no pesticide application, and the second one consists of the application of a foliar fertilizer (Nitromyel 30-00 ) applied directly to the leaves of the plants, which is suitable for ecological regimes. In this crop, all the wheat straw is left in the field and only the grain is obtained as product.

In all winter wheat case studies, sun drying is the drying method for reducing the moisture content of the grains (finally the moisture content is around $12 \%$ ). The dried grains are then stored in silos for one year before being sold to bread producers. The crops are rain-fed so there is no irrigation equipment involved.

The agronomic inputs for each crop growth (C-WW, Gc-WW and Ge-WW) are shown in Tables SM1-SM3 in the Supplementary Material, where the features of the specific agricultural machines commonly used for these crops are summarized. The use of crop residues as mulch has numerous benefits for the soil and the environment due to their content of nutrients such as N, P and K, as well as C, which can nourish the subsequent crop in the rotation as explained in Section 2.4.1. Table 1 shows the different combinations for WW cultivation. C-WW1, Gc-WW1 and Ge-WW1 were modelled after potato as the preceding crop and did not receive any input of straw. Conversely, C-WW2, Gc-WW2 and GeWW2 were modelled after WW as a preceding crop and received wheat straw (15\% in C-WW2 and 100\% in the others). Regarding WW crops cultivated under rotation with maize and oilseed rape (C-WW3, C-WW4, Gc-WW3, Gc-WW4, Ge-WW3 and Ge-WW4), they received straw from the preceding crops. As a result, nine different scenarios were defined. 


\subsubsection{Crop rotation systems}

As detailed above, nine different rotation systems were formulated based on the combination of winter wheat (WW) with potato, maize or oilseed rape. The C-WW and Gc-WW rotations showed no difference in cultivation practices, as both were under conventional management and, therefore used agrochemicals. Conversely, in the rotations including Ge-WW, specific organic fertilizers were applied. All nine scenarios were cultivated in a six-year rotation cycle. Scenarios S1-S6 were performed under conventional management and S7-S9 under an ecological regime.

A six-year rotation cycle based on WW and potato (S1, S4 and S7) consisted of two continuous years of WW (year 1, year 2, year 4 and year 5) followed by one year of potato (year 3 and year 6 ). Regarding the six-year rotation cycles based on WW with maize (S2, S5 and S8) and oilseed rape (S3, S6 and S9), they were alternately cultivated, i.e. one year of WW is followed by one year of the alternate crop (maize or oilseed rape), as detailed in Table 1.

2.3.2.1. Potato under conventional management ( $P 1$ and $P 2$ ). Potato cultivation under conventional management is considerably mechanical, involving multiple soil preparation activities, the application of mineral fertilizers (NPK 9-18-27 and calcium ammonium nitrate) and other agrochemicals (up to seven) as detailed in Table SM4 in the Supplementary Material. Field establishment requires mouldboard and chisel ploughing, as well as a mineral fertilization and milling before sowing (1200-1500 kg seeds $\cdot \mathrm{ha}^{-1}$ ) in May. It is important to note that the cultivation of potatoes receives $15 \%$ and $100 \%$ of the wheat straw produced in C-WW2 (P1) and Gc-WW2 (P2), respectively. Harvesting is performed in September and the biomass yield is on average $35 \mathrm{t} \cdot \mathrm{ha}^{-1}$ ( $80 \%$ moisture), of which $10 \%$ is used for animal feed since it does not meet the quality requirements for human consumption.

2.3.2.2. Maize under conventional management (M1 and M2). The production of maize silage under conventional management is detailed in Table SM5 in the Supplementary Material. It requires large amounts of mineral fertilizers (NPK 8-15-15 and calcium ammonium nitrate) and agrochemicals, and numerous agricultural activities such as mouldboard and chisel ploughing and soil tillage. Sowing is performed in May and this activity is combined with the application of an insecticide. The harvest is done in October and the average yield is about $30 \mathrm{t} \cdot \mathrm{ha}^{-1}$ of maize silage ( $70 \%$ moisture content) which is baled. In addition, $5 \mathrm{t} \cdot \mathrm{ha}^{-1}(15 \%$ moisture content) of the maize straw is left on the field as nutrient supplier for the following crops in the rotation (i.e. C-WW3 and Gc-WW3). However, the cultivation of maize also receives an input of wheat straw from previous crops: 15\% from C-WW3 (in M1) and 100\% from GcWW3 (in M2).

2.3.2.3. Oilseed rape under conventional management (OSR1 and OSR2). The production of oilseed rape requires fewer agricultural activities than potatoes or maize. Sowing ( $4 \mathrm{~kg}$ seeds $\left.\cdot \mathrm{ha}^{-1}\right)$ is performed in September (combined with soil tillage) after chisel ploughing and mineral fertilization with NPK (8-15-15). There is a post-emergence mineral fertilization with calcium ammonium nitrate and application of herbicide. Finally, harvesting is in July and the average yield is $3.5 \mathrm{t}$ oilseeds $\cdot \mathrm{ha}^{-1}$. The straw produced $\left(9 \mathrm{t} \cdot \mathrm{ha}^{-1}, 20 \%\right.$ moisture content) is left entirely in the field as a nutrient supplier for the next crop in the rotation system (i.e. winter wheats C-WW4 and Gc-WW4). The crop also receives straw from the previous crop (15\% and 100\% of the straw produced in C-WW4 (for OSR1) and in Gc-WW4 (OSR2), respectively). A summary of the agricultural activities involved is detailed in Table SM6 in the Supplementary Material.

2.3.2.4. Potato, maize and oilseed rape under ecological management ( $P 3$, M3 and OSR3). Changes in soil quality and productivity can provide critical signs of environmental degradation. In this regard, changes in soil structure through conventional agricultural management practices (use of agrochemicals and intensive agricultural activities) intensify surface runoff, loss of nutrients and soil to water bodies. Incorporating ecological management into intensive farming systems can improve soil quality with sustained productivity (Bhardwaj et al., 2011). Organic farming involves the production of a crop without the use of synthetic chemical fertilizers and maximises the use of ecological interactions. Three rotation systems include ecological management which are S7S9, where Ge-WW is combined with P3, M3 and OSR3, respectively. Considerable differences from conventional management can be identified for each alternative crop. In the case of potato (P3, see Table SM7 in the Supplementary Material), the main difference is the application of an organic fertilizer (poultry manure from organic farms) and a mineral fertilizer (PatentKali 30\%) which is allowed in organic crop production. Moreover, there are fewer applications of insecticides and fungicides but there is an additional mechanical treatment to remove weeds. The cultivation of potatoes under ecological management (P3) receives an input of wheat straw (100\%) from the previous crop Ge-WW2. The yield of the potatoes is considerably reduced to $43 \%$ (20 $t \cdot \mathrm{ha}^{-1}, 80 \%$ moisture where $10 \%$ is destined to animal feed).

Concerning organic maize (M3, see Table SM8 in the Supplementary Material), mineral fertilizers are substituted by two applications of ecological manure (poultry and cattle) before sowing. Only one mechanical treatment and one insecticide treatment are carried out before harvesting. The cultivation of maize under ecological management (M3) receives an input of wheat straw (100\%) from the previous crop Ge-WW3. The maize silage yield is $25 \mathrm{t} \cdot \mathrm{ha}^{-1}$ and $2.5 \mathrm{t} \cdot \mathrm{ha}^{-1}$ of maize straw is left on the field.

Finally, the cultivation of ecological oilseed rape (OSR, see Table SM9 in the Supplementary Material) includes two organic fertilizations with ecological manure before sowing, which is combined with soil tillage. After sowing, there is a mechanical treatment, removing the use of agrochemicals. The cultivation of OSR under ecological management (OSR3) receives an input of wheat straw (100\%) from the previous crop GeWW4. The oilseeds yield is $2.5 \mathrm{t} \cdot \mathrm{ha}^{-1}$.

\subsection{Life cycle inventory analysis and assumptions}

Fig. 1 illustrates the boundary of the agricultural systems at farm gate. The life cycle assessment of each crop in the rotation comprised the extraction of raw materials (e.g. fossil fuels and minerals), manufacture (e.g. seeds, mineral fertilizers, herbicides, insecticides, fungicides and agricultural machinery), use (tailpipe emissions and tyre abrasion emissions), maintenance and final disposal of the machines. Information regarding operation hours, diesel consumption, amounts of agrochemicals applied and yields of products and by-products was provided directly by farmers through surveys and interviews. This information is summarized in Tables SM1-SM9 in the Supplementary Material and corresponds to primary data for the foreground systems. The calculation of the machinery used (tractors, trailers and implements) in each agricultural activity was carried out according to the Ecoinvent database ${ }^{\circledR}$ considering the weights, operation hours and lifetimes of the machinery.

Although the use of primary data is recommended, it was necessary to consider secondary data to complete the inventory tables. Secondary data were handled for the background system that comprises the activities required to produce all the inputs to the farming systems (i.e. diesel, machinery, agrochemicals), as well as to estimate the tailpipe emissions. The Ecoinvent ${ }^{\circledR}$ database version 3.5 (Wernet et al., 2016) was considered as the main secondary data source.

For the application of manure in the organic regime (S7-S9, see Table 1), poultry and cow manure were considered. Both come from farming activities which are multifunctional activities. Bearing in mind the information supplied by farmers, 50\% of the manure must be used for energy purposes on poultry and dairy farms, with the remaining $50 \%$ derived from fertilization when the organic regime is established and receiving an economic revenue from this procedure. Consequently, the environmental burdens resulting from agricultural activities were 


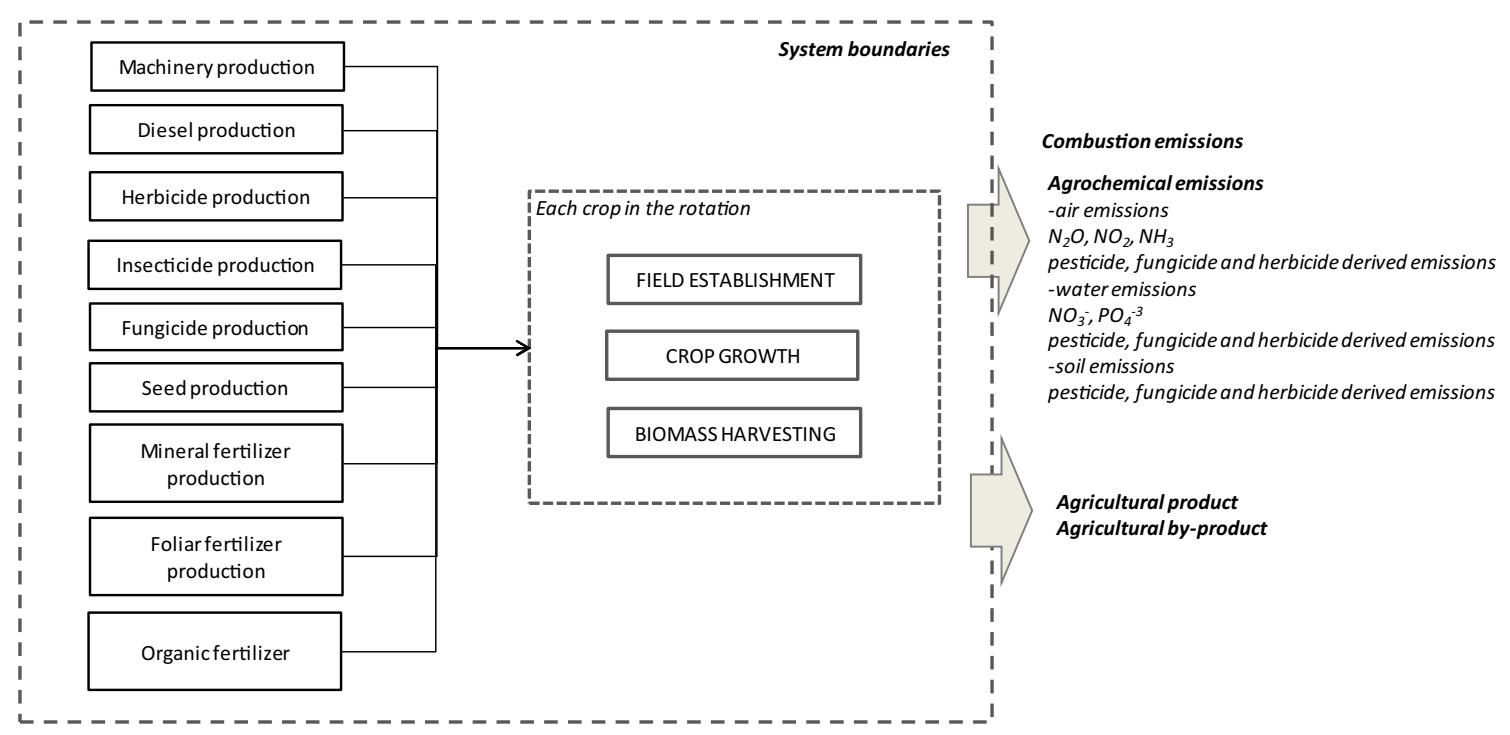

Fig. 1. Main processes considered within the system boundary of each analysed crop with the rotation cropping systems under study.

shared among the co-products (manure, electricity and animal products) according to an economic allocation approach. To this end, the economic data provided by the farmers involved were managed. Consequently, a factor of $1.0 \%$ was established for poultry manure considering the inventory data of the poultry farm of Gonzalez-Garcia et al. (2014). Concerning the dairy farm, an allocation factor of $4.1 \%$ was estimated for the cow manure considering inventory data from Cortés et al. (2020).

\subsubsection{Effect of crop residues and land use}

Approximately, $9 \%$ of global carbon emissions derive from land use changes. Despite the common practice of excluding LUC emissions in the LCA of agricultural products (Schmidt et al., 2015), it is a relevant source of impacts to include when assessing agricultural systems, particularly because the results vary considerably. There are two types of land use change caused by land occupation: direct land use change (dLUC) and indirect land use change (iLUC). The dLUC is associated with changes in the carbon content of biomass and soil and iLUC refers to those carbon changes that occur indirectly elsewhere (Schmidt et al., 2015). Both LUCs have been considered in our system boundaries considering the changes in soil carbon content due to straw being returned into the field, as detailed above. In our study, a single emission factor has been estimated for iLUC under an attributional LCA approach for agricultural land of $289 \mathrm{~kg} \mathrm{CO}_{2} \mathrm{eq} \cdot \mathrm{ha}^{-1}$ of agricultural land used per cropping system over a period of 6 years, which was estimated based on a biophysical seven steps-model developed by Schmidt et al. (2015).

During WW in S4-S9 only grain was harvested, while straw was left in the field. In S1-S3 85\% of the straw was baled and collected for animal feed, while the remaining $15 \%$ was left in the field. For rapeseed and potatoes, only seeds and tubers were collected, respectively, while crop residues (straw and leaves) had the same fate as wheat straw in S4S9. In the case of maize, the main product is the silage, so whole maize plants were removed, although a small amount of biomass was left in the field, as described above. The straw returned to the field modifies the soil organic composition, improving its soil quality, since it partially remains at the end of that season. The amount of wheat straw left after the season (i.e., straw decomposition) depends on multiple factors (Jin et al., 2020). In this study, it was assumed that the residual percentage of straw is approximately $16 \%$ that will be stored in the soil in the long term (Fang et al., 2019) and a carbon content of straw of $49 \%$ of its dry matter (Brandão, 2012; IPCC, 2019). The increase in the soil carbon content was managed as an environmental credit in the results, assuming that the soil is absorbing the carbon. The remaining $84 \%$ of the carbon in the straw should be emitted. Nevertheless, this issue was not considered in the evaluation since no sequestration was considered either and both flows occur in the same year. The breakdown of straw in the following years was not considered for the same reason: it is balanced by carbon sequestration.

\subsubsection{Direct and indirect field emissions}

An important issue in LCA applied to agricultural systems is the estimation of field emissions. Accordingly, field emissions due to the application of fertilizers and other agrochemicals were included in the assessment. $\mathrm{N}_{2} \mathrm{O}$ emissions were estimated according to the Intergovernmental Panel on Climate Change (IPCC, 2019). $\mathrm{NO}_{2}$ and $\mathrm{NH}_{3}$ emissions were calculated as proposed by the European Environmental Agency and European Monitoring and Evaluation Programme (EMEP/ EEA, 2019). $\mathrm{NO}_{3}^{-}$leaching (Faist Emmenegger et al., 2009) and phosphate $\left(\mathrm{PO}_{4}^{-3}\right)$ leaching and runoff (Prasuhn, 2006) were also considered. Pesticides, fungicides and insecticides related emissions into air, water and soil were estimated according to PEFCR guidance (2017) and heavy metal emissions were not accounted for. Background information concerning procedure followed for the estimations and emission factors managed is detailed in the Supplementary Material (Section B and Table SM10 respectively).

\subsection{Market value of products and by-products and production costs}

The crops included in the rotation systems yield more than one co-product with market price. This is the case of the commercial WWs (C-WW1-4) that yield WW grain $\left(0.20 € \cdot \mathrm{kg}^{-1}\right)$ and WW straw $\left(0.07 € \cdot \mathrm{kg}^{-1}\right)$. In the case of potatoes, $10 \%$ of tuber yield does not meet food quality standards and is sold for animal feed. The price of potatoes for human consumption is $0.12-0.20 € \cdot \mathrm{kg}^{-1}(\mathrm{P} 1$ and P2) and $0.25-0.30 € \cdot \mathrm{kg}^{-1}(\mathrm{P} 3)$. When sold for feed consumption, the price is $0.05 € \cdot \mathrm{kg}^{-1}$. In the case of maize and oilseed rape, the straw is returned to the field (only partly in the case of maize); only maize silage $\left(0.06 € \cdot \mathrm{kg}^{-1}\right.$ for M1 and M2 and $0.09 € \cdot \mathrm{kg}^{-1}$ for M3) and oilseed $\left(0.30 € \cdot \mathrm{kg}^{-1}\right.$ for OSR1 and OSR2 and $0.40 € \cdot \mathrm{kg}^{-1}$ for OSR3) are obtained as main products. Regarding the native WWs (Gc-WW and Ge-WW), only grain is obtained as product.

The straw is left in the soil as a nutrient supplier. The grain is sold at $0.40 € \cdot \mathrm{kg}^{-1}$ when it comes from conventional management (Gc-WW1-4) and at $0.48 € \cdot \mathrm{kg}^{-1}$ when it is from ecological management (Ge-WW1-4). When the straw is incorporated in the soil, it is not a co-product and there is no economic revenue (i.e., in GcWW1-4, Ge-WW1-4, M1-3 and OSR1-3). A summary of the amount 


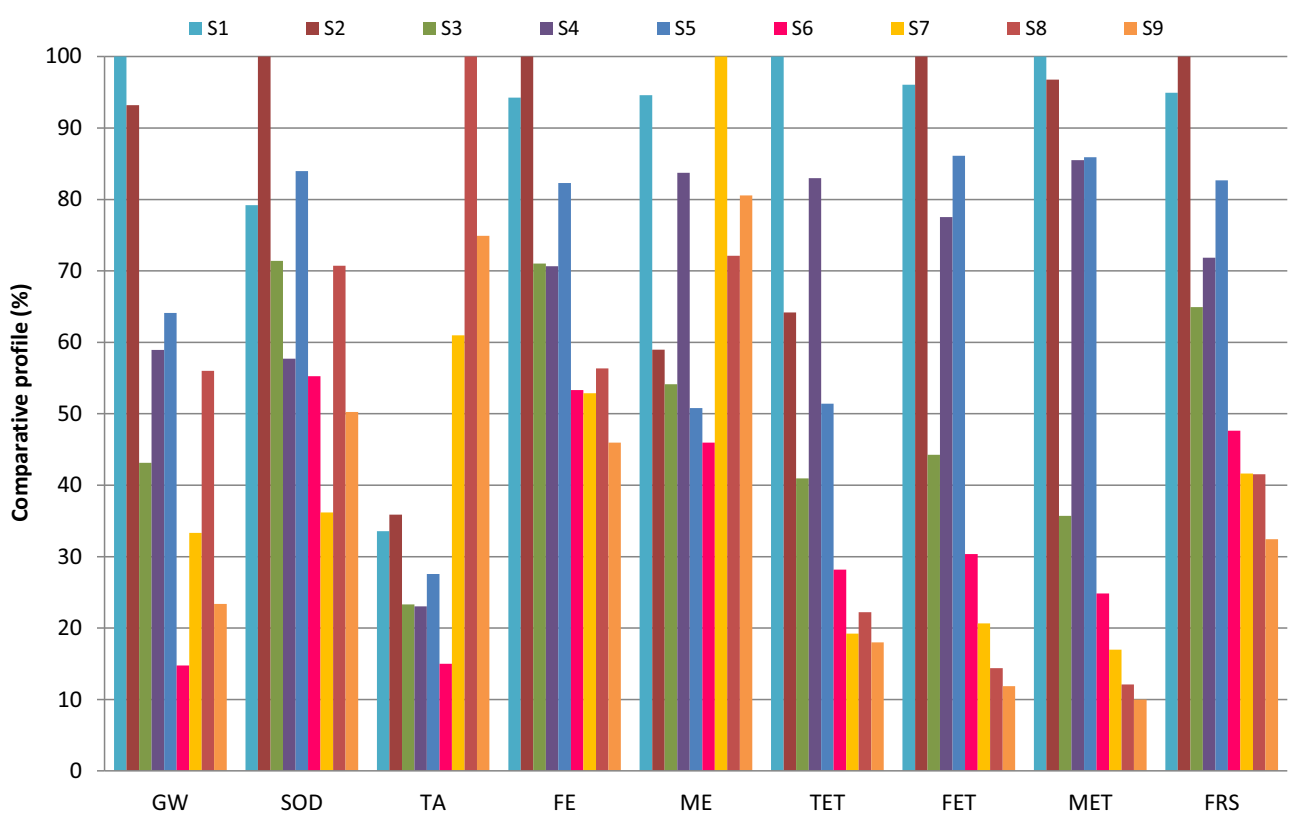

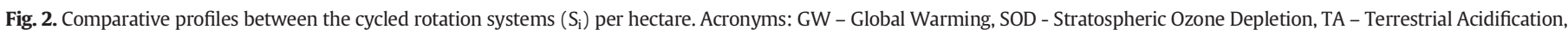
FE - Freshwater Eutrophication, ME - Marine Eutrophication, TET - Terrestrial Ecotoxicity, MET - Marine Ecotoxicity, FRS - Fossil Resource Scarcity.

of co-products and yields per scenario, i.e. per rotation cycle, is shown in Table 1. Activity costs per agricultural operation (including diesel, machinery and personal costs) and input costs (e.g., agrochemicals, seeds and manure) are detailed for each individual crop in the Supplementary Material (Tables SM1-SM9).

\subsection{Environmental assessment method}

Two impact assessment procedures were considered in the analysis. Firstly, the ReCiPe 2016 hierarchist Midpoint method V1.03 World (2010) (Huijbregts et al., 2017) was used for the selection of characterization factors required to estimate the environmental burdens and a set of impact categories at midpoint level commonly used in the environmental analysis of agricultural systems was considered for reporting the environmental profiles: global warming (GW), stratospheric ozone depletion (SOD); terrestrial acidification (TA), freshwater eutrophication (FE), marine eutrophication (ME), terrestrial ecotoxicity (TET), freshwater ecotoxicity (FET), marine ecotoxicity (MET) and fossil resource scarcity (FRS). The choice of these categories allowed the comparison with other related agricultural studies available in the literature.

Secondly, the normalization factors from this method have been considered to establish a final ranking of cropping systems. This approach is contemporary, widely used and well recognized (Kalbar et al., 2016). The choice of this normalization approach is because having only one single adimensional score for the overall impacts can help disseminate the message to the audience better. The SimaPro software v9.0 (PRé Consultants, 2020) was used for the computational implementation of the life cycle inventories.

\section{Environmental results and discussion}

The environmental profiles for each rotation system were reported in terms of nine impact categories. Firstly, crop rotations per hectare were analysed to answer the question focused on land management, which allowed for the identification of the crop rotations with the best and the worst environmental profiles. In addition, a detailed assessment was conducted with the aim of identifying the activities or processes that contribute most to these environmental burdens. Secondly, profiles were normalized per $€$ of gross margin to give an answer to the financial question.

\subsection{Environmental profile of the rotation cycles}

\subsubsection{General comparison}

Fig. 2 displays the comparative profile between the different crop rotations being studied in relation to the different impact categories. The comparison was performed in terms of hectare (ha). It is important to note that the consideration of this functional unit penalizes the crops with higher yields. For example, the commercial WW (crops C-WW1 and C-WW2) with maize (i.e. S2) is the scenario with the worst profile, as it reports the highest burdens in numerous impact categories. Similarly, $\mathrm{S} 1$, where the same WW variety is cultivated but in rotation with potato, should be the second worst cultivation option, reporting the worst scores in categories such as GW, TET and MET. The cultivation of this wheat variety requires multiple mechanized applications of mineral fertilizers (400 $\mathrm{kg} \cdot \mathrm{ha}^{-1} \mathrm{NPK}$ and $200 \mathrm{~kg} \cdot \mathrm{ha}^{-1} \mathrm{CAN}$ ) and other agrochemicals (two herbicide applications and one fungicide dosage) compared to the native variety (see Tables SM1-SM3 in the Supplementary Material), which is one of the reasons behind these profiles. In addition, differences in the profiles of scenarios that include C-WW (S1-S3) are directly associated with the crop included as alternative in the rotation. As shown in Tables SM4-SM6 of the Supplementary Material, for potato, maize and oilseed rape under conventional management, the cultivation practices and thus, the degree of mechanization change considerably between them. Potato cropping requires a considerable level of mechanization and input use, with up to seven agrochemical applications (other than fertilizers) by means of an hydraulic sprayer connected to a tractor, two mineral fertilizations ( $800 \mathrm{~kg} \cdot \mathrm{ha}^{-1} \mathrm{NPK}$ and $\left.250 \mathrm{~kg} \cdot \mathrm{ha}^{-1} \mathrm{CAN}\right)$, as well as numerous soil conditioning activities (mouldboard and chisel ploughing, and tillage). The number of agrochemical ${ }^{2}$ applications is reduced in the case of maize and mainly for oilseed rape, where there is only one application of herbicide; the demand for mineral fertilizers is considerably reduced ( $350 \mathrm{~kg} \cdot \mathrm{ha}^{-1} \mathrm{NPK}$ and $200 \mathrm{~kg} \cdot \mathrm{ha}^{-1} \mathrm{CAN}$ ) and fewer soil establishment activities are performed (only chisel ploughing and milling is combined with sowing). These differences justify the lowest environmental burdens per hectare for S3 (rotation with rapeseed) compared to S1 (rotation with potato) and S2 (rotation with maize).

\footnotetext{
${ }^{2}$ From now, the term "agrochemicals" includes all applied chemicals, other than fertilizers.
} 
As for the S8, where the native WW variety (Ge-WW3) is combined with maize (M3) under the organic regime, this scenario reports the worst profile in terms of TA. The reason is associated with the use of animal manure as fertilizer, mainly in maize crop. In this scenario, large amounts of manure are required $\left(5 \mathrm{~m}^{3} \cdot \mathrm{ha}^{-1}\right.$ of organic poultry manure in Ge-WW3 and, $8 \mathrm{t} \cdot \mathrm{ha}^{-1}$ of ecological poultry manure and $15 \mathrm{~m}^{3} \cdot \mathrm{ha}^{-1}$ of ecological cow manure in M3), which implies outstanding field emissions of ammonia into air (main hotspot in TA, 79\% of total contributing emissions), among others. S7, where the autochthonous variety of WW is combined with potato (P3) reports the worse score in ME, mainly due to field emissions from manure use, specifically nitrate leaching.

Crop rotations with oilseed rape (S3, S6 and S9) have the best results, in which the rotations with the native WW variety (S6 and S9) appear to be the most favourable in various impact categories (such as GW, TA FRS as well as toxicity and eutrophication related categories). In this sense, the cultivation of oilseed rape (OSR1, OSR2 and OSR3) requires fewer mechanical activities (and, therefore, less diesel), fertilizers and agrochemicals than maize and potato, resulting in lower environmental burdens. Among them, S9, where rapeseed (OSR3) is combined with the native wheat variety under ecological management (Ge-WW4) appears to be the best choice for land use, i.e. the cropping system that reports the lowest environmental burdens (in four of nine impacts analysed).

Regardless the variety of WW cultivated in a rotation with potato (S1, S4 and S7), the cultivation of the latter is in general responsible for the highest environmental burdens from the rotation, i.e. it is responsible for the largest contributions to the different impact categories, as detailed in Fig. 3, and especially in the categories related with toxicity in S1 and S4. The reason for this result is associated with the extensive requirement of fertilizers and agrochemicals for the cultivation of potato under the non-organic regime.

Nevertheless, even under organic management, the cultivation of potato plays a key role in the environmental profile of S7 since this crop demands more inputs and mechanized activities than winter wheat. In addition, and noting the profiles and contributions to the rotation, the WW grew after another previous WW crop (i.e., WW2 regardless of the management regime) reports a slight improvement in GW per hectare in comparison with the preceding one (i.e., WW1), due to the effect of the return of the straw to the field and the corresponding environmental benefits allocated to this issue (the effect from the increment in the soil organic carbon content due to the return of the straw to the field is assigned to the next crop, which implies an environmental credit).

The profiles of the scenarios including maize (S2, S5 and S8) and oilseed rape (S3, S6 and S9) are dominated by the contributions from the cultivation of the alternate crops (see Figs. 4 and 5). The effect of maize is significant, as it is a crop with a high demand for agrochemicals (insecticides, fertilizers and fungicides) compared to WW. Therefore, its effect on toxicity-related impact categories TET, MET and TET is notable. The production of the required mineral fertilizers in maize produced under conventional management (S2 and S5) also plays a key role specifically in categories such as GW, OSD, TA, FE and FRS. The behaviour under organic regime (S8) undergoes a slight change mainly in the categories related to toxicity due to the use of organic fertilizers. Consequently, the effect of wheat cultivation on the rotation profile under ecological management is more noticeable in some impacts such as ME, FRS and toxicity related categories than in the other scenarios with maize.

Concerning oilseed rape, the cultivation under conventional and organic regimes requires significant applications of fertilizers (mineral and organic) but low requirements for other agrochemicals. Thus, there are large emission rates of field emissions from fertilization, which penalizes their environmental profile in comparison with the corresponding wheat (in special in S6). Special attention should be given to the environmental credits identified in GW due to the return of straw to the field, which contributes to increase the carbon content of the soil. This effect is noticeable at S6 and S9 in the WW cultivation due to the reception of large amounts of rapeseed straw.

\subsubsection{Contributing parameters to the environmental profiles}

The environmental profiles are determined, as displayed in Fig. 6, by field emissions and by the production of fertilizers (especially N-based

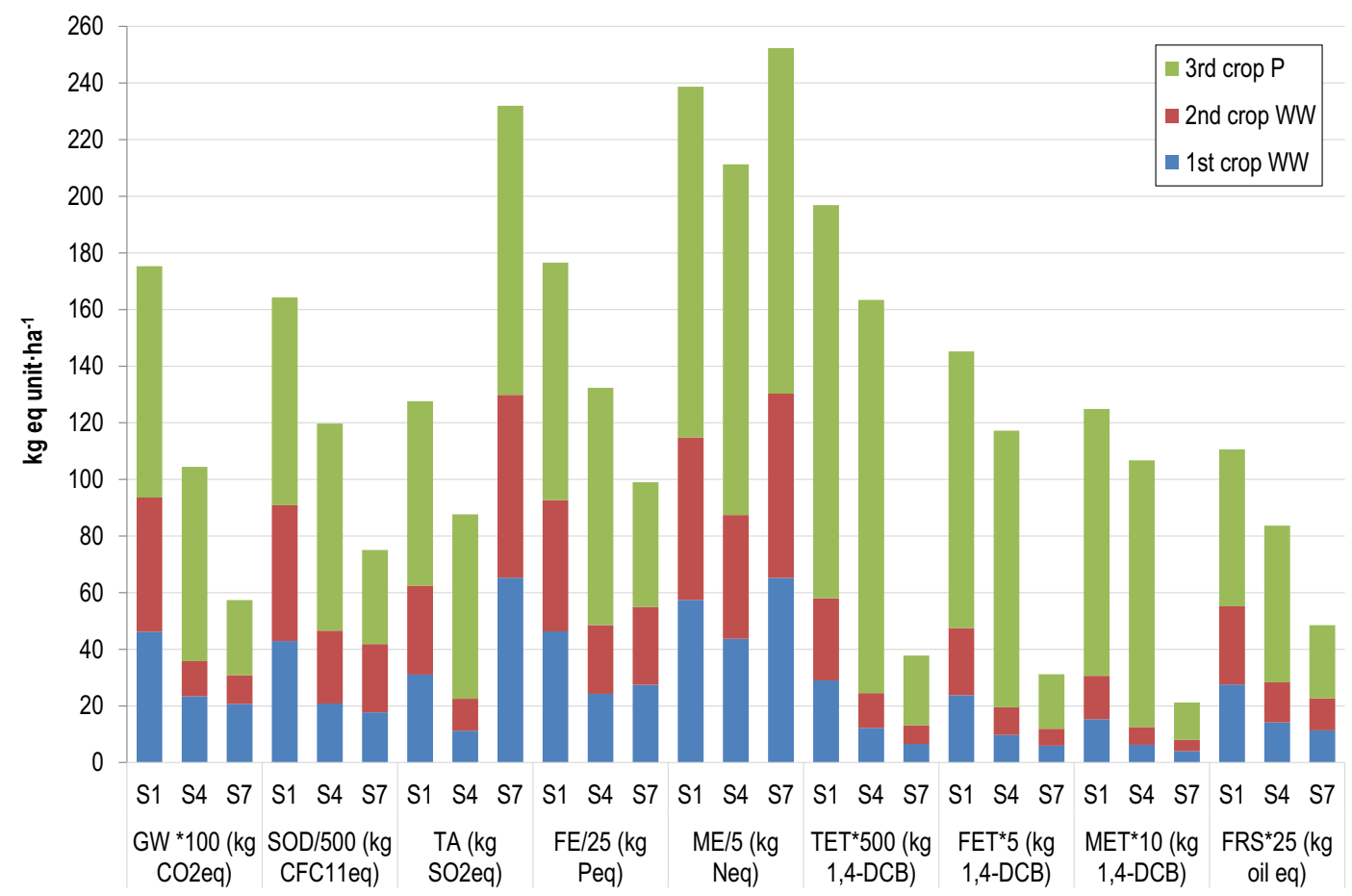

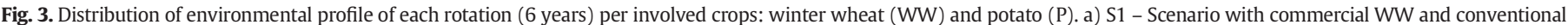

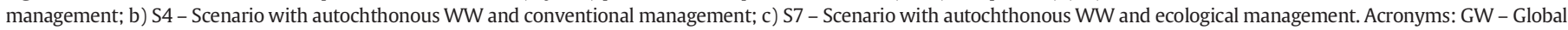

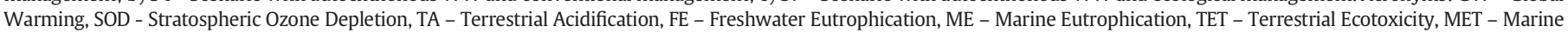
Ecotoxicity, FRS - Fossil Resource Scarcity. 


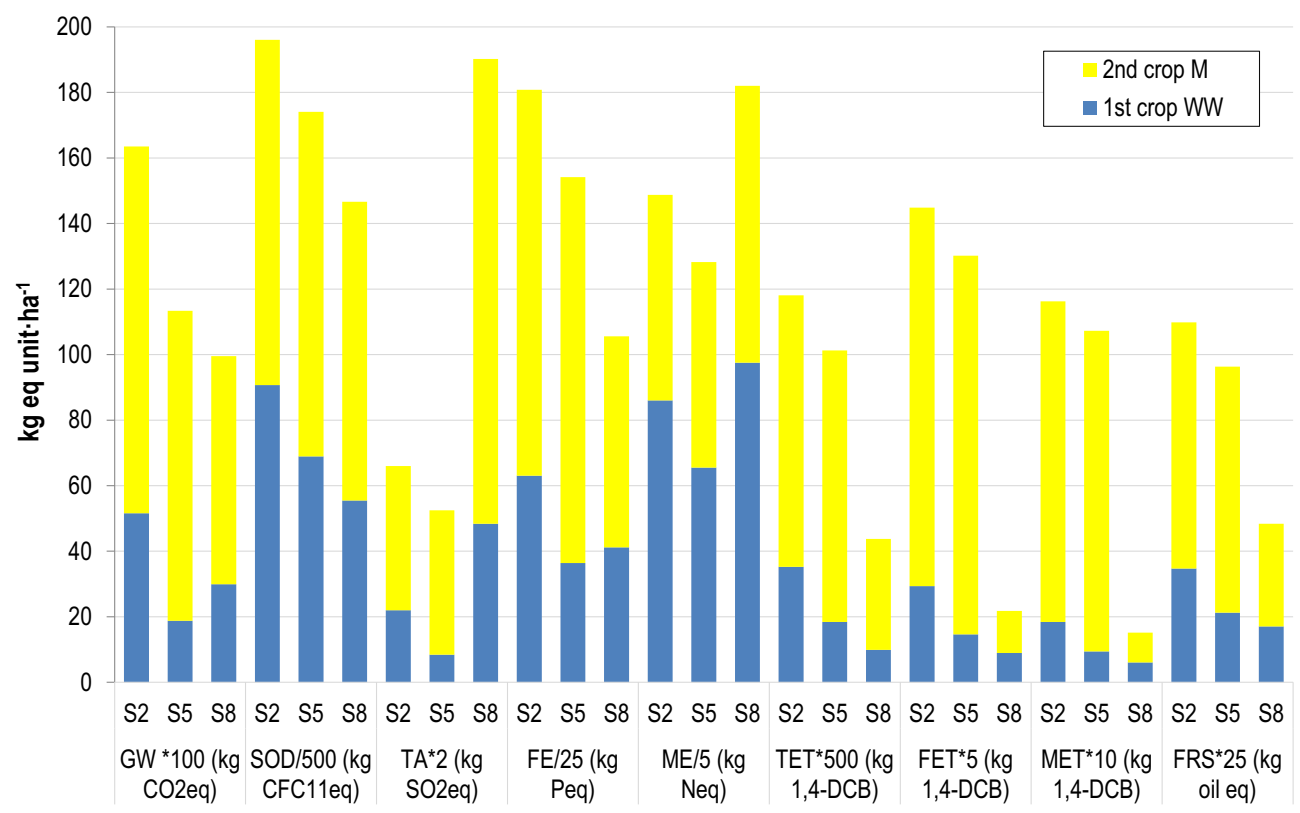

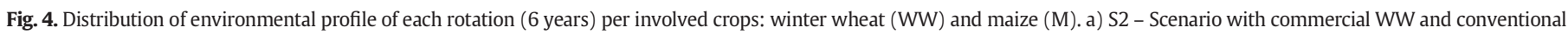

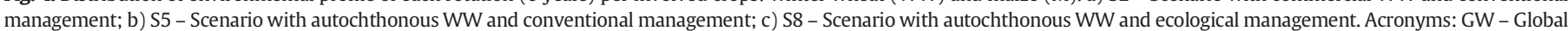

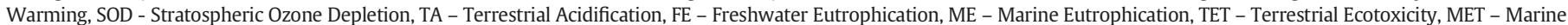
Ecotoxicity, FRS - Fossil Resource Scarcity.

fertilizers). Regarding the latter, the effect of organic fertilizers in toxicity-related categories such as FET and MET, is less outstanding than that from mineral fertilizers. The production of the required agrochemicals (insecticides, pesticides and fungicides) has an unremarkable effect on the profile, regardless of the scenario under study.

Mechanization activities are not very relevant, except in toxicityrelated categories and FRS due to diesel consumption and corresponding tail pipe emissions. Within the agricultural activities performed in the field, harvesting plays a key role -regardless of the crop - followed by mouldboard ploughing and soil tillage (all activities that require large amounts of diesel due to long hours of operation). When a baling operation is required as in $\mathrm{S} 1-\mathrm{S} 3$, the effect of this activity is also remarkable.
Noting the contribution analysis depicted in Fig. 6, field emissions are the largest contributor to the environmental burdens (except in FRS). This contributing factor includes air, water and soil emissions derived from the application of fertilizers, agrochemicals and from the straw decomposition as well as the iLUC ( $289 \mathrm{kgCO}_{2}$ eq per system). Regarding these emissions, $\mathrm{N}_{2} \mathrm{O}$ derived from the application of nitrogen-based fertilizer (organic or inorganic) and straw is the most critical emission, specifically in GW and OSD. Concerning TA, attention should be paid to $\mathrm{NH}_{3}$ and $\mathrm{N}_{2} \mathrm{O}$ emissions derived from $\mathrm{N}$-fertilization. Consequently, the mechanized operations developed in the field were less important for these impact categories due to the low impact of tail-pipe emissions compared to those from fertilizer application.

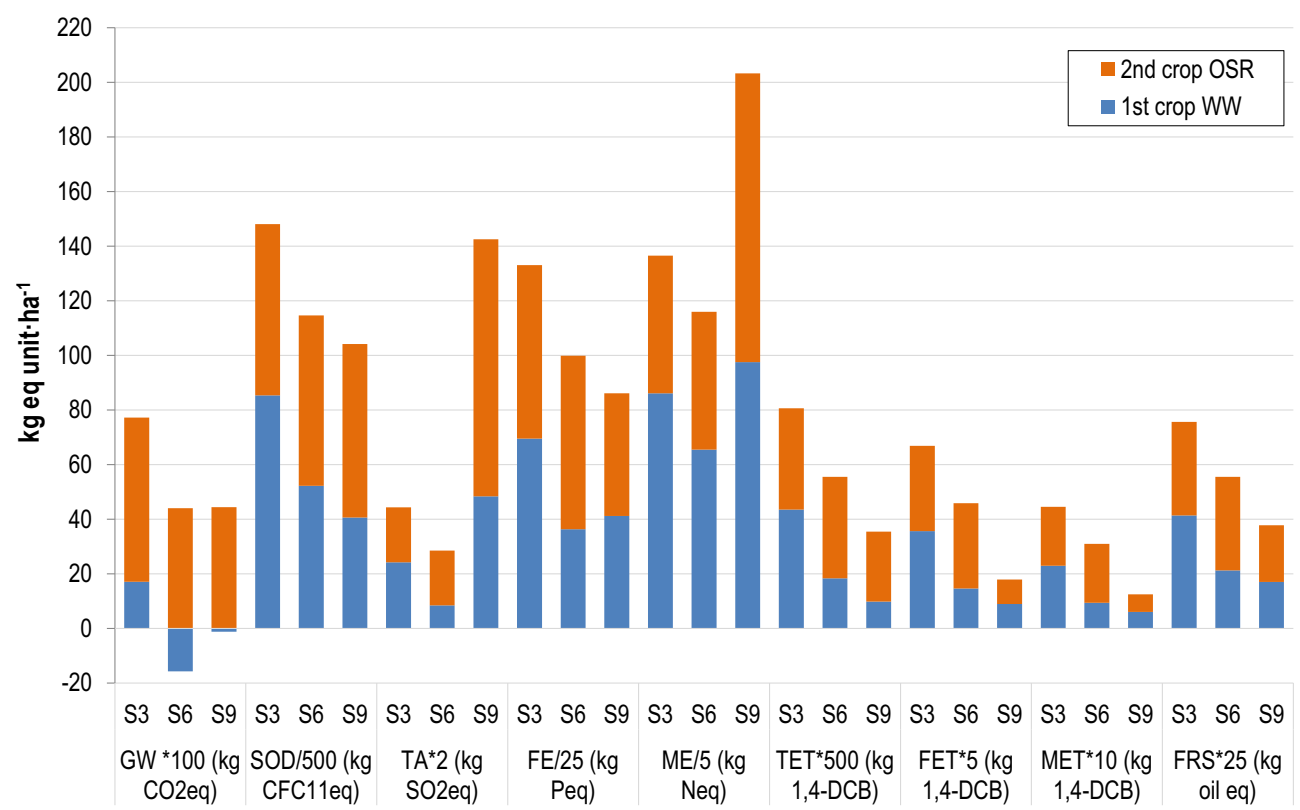

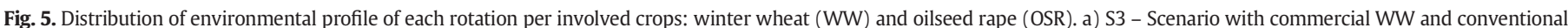

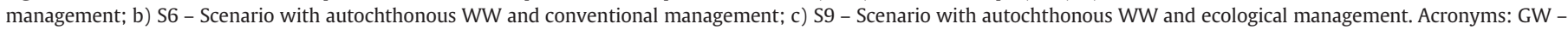

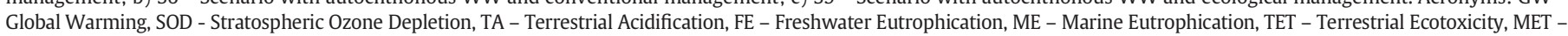
Marine Ecotoxicity, FRS - Fossil Resource Scarcity. 


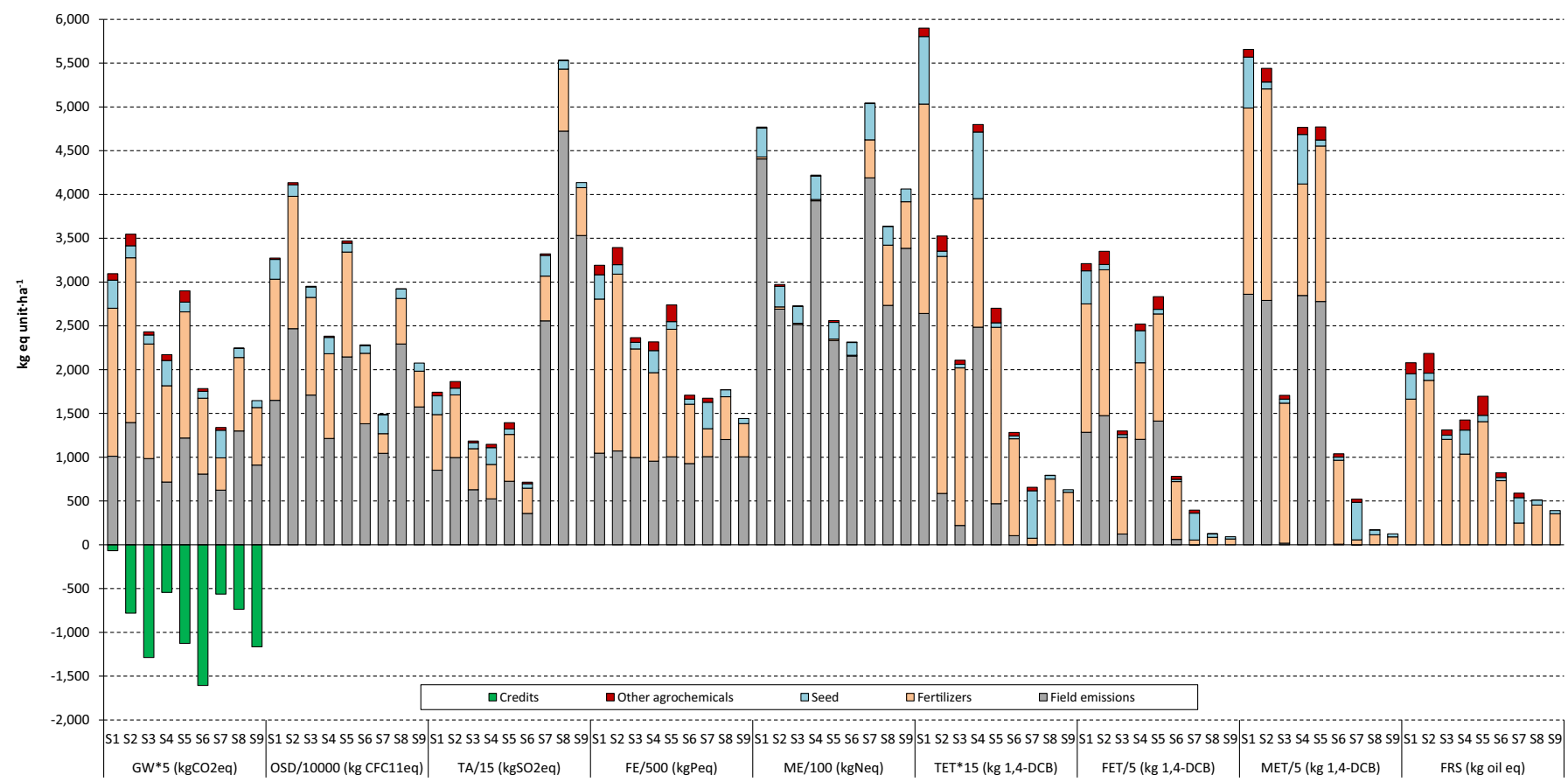

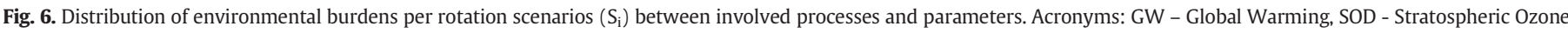

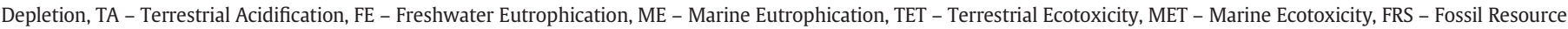
Scarcity.

In the eutrophication-related categories, phosphate and nitrate emissions into water are the hotspots in FE and ME respectively. Therefore, the nitrogen and phosphorus fertilization are considerably relevant over the global environmental profile of these cropping systems. Regarding the application of agrochemicals, derived emissions into soil of the active ingredient are the main responsible contributors to toxicity-related categories, whenever they are applied (see S1-S6).

Another parameter to be discussed is linked to the credit linked to returning straw after harvesting into the soil and the corresponding increment in the soil carbon content, whose effect is quite relevant in the GW profile, contributing to reducing the GHG emission per cropping system. The carbon stored in the soil due to straw deposition ranges from $-334 \mathrm{kgCO}_{2} \mathrm{eq} \cdot \mathrm{ha}^{-1}$ (S1) to $-8.03 \mathrm{tCO}_{2} \mathrm{eq} \cdot \mathrm{ha}^{-1}(\mathrm{~S} 6)$.

\subsection{Environmental profile of the crop rotation per $€$ of gross margin}

Firstly, the gross margin is calculated per cropping system. Thus, the total production costs including activity (diesel, machinery use and personal) and input costs (seeds, agrochemicals and manure) are taken into account and subtracted from the total revenue from sales of products. Fig. 7 displays the distribution of costs and revenues per cropping system, sharing between the main crop (winter-wheat) and the alternate crop. Accordingly, all scenarios involve a positive gross profit

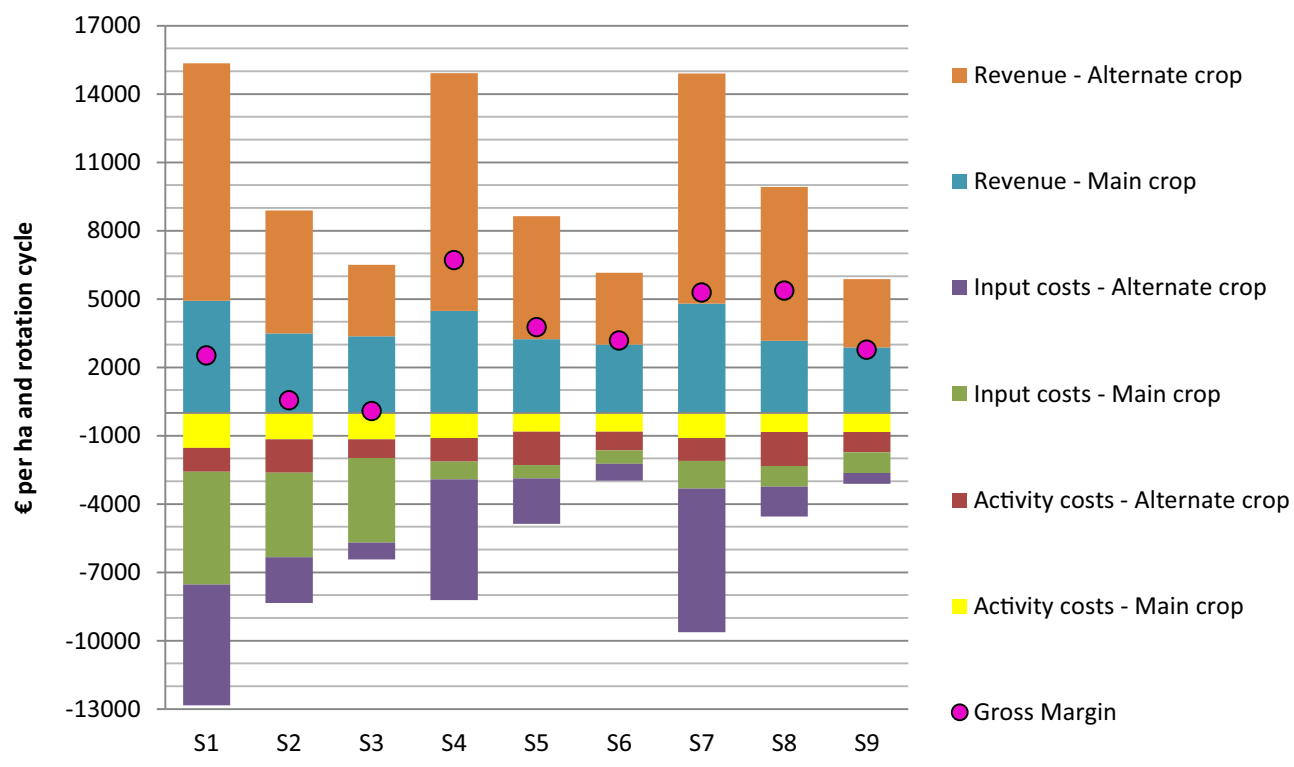

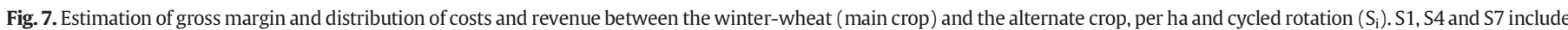
potato as alternate crop; S2, S5 and S8 include maize as alternate crop; S3, S6 and S9 include oilseed rape as alternate crop. 
ranging from $70 €$ in S3 to $6698 €$ in S4. Therefore, the total costs are lower than revenue and it derives into very different economic benefits. Gross margin is higher, if considering the same variety (commercial or native), when potato constitute the alternate crop in the rotation. On the other hand, the gross margin is higher if considering the same alternate crop, when the native WW variety is present in the rotation instead of the commercial one.

In addition, and bearing in mind the figure, activity costs dominate the costs in those scenarios that include the native WW variety combined with maize and rapeseed (e.g., S5, S6, S8 and S9). In those scenarios where native WW is combined with potato, the costs associated with the cultivation of the alternate crop are quite remarkable. The alternate crop is responsible for $77 \%$ in S4 and S7 of total costs derived from the rotation system. In general lines and as difference to these scenarios where commercial WW is cultivated, when native variety is present in the rotation, the total costs are dominated by those associated with the alternate crop, especially when potato and maize constitute the alternate crops (see Fig. 7). The rationale behind these results is linked with the high doses of agrochemicals and agricultural activities required in the cultivation of potato and maize in comparison with the native WW. Moreover, the rapeseed does not present the same level of intensity than the other two. Concerning the revenue from sales, it is higher for those scenarios where the cultivation of winter-wheat (within the same variety) is combined with potato, mainly because of the large production yield associated with this alternative crop and market price in comparison with the other two crops.

Recalculating the results per $€$ of gross margin, does not change the relative contributions of different processes or emissions involved to the overall impact, but it could change the ranking of the cropping systems bearing in mind the results summarized in Table 2. According to our results, the ranking of crop rotations entirely changes and thus, so does the decision supported by this study when shifting to a financial unit, i.e., $€$ of gross margin. The crop rotations including the native $\mathrm{WW}$ variety are those with best environmental profiles. By far, S3 where commercial WW variety is combined with rapeseed is the cropping system with the highest environmental burdens, regardless of the impact category. This scenario is the one with the lowest gross margin (70€ per ha and rotation system).

Scenarios that include Galician WW variety under ecological regime can be considered, in general lines, as the most environmental-friendly scenarios ones. In special S7 which combine the WW with potato (GeWW1 + Ge-WW2 + P3). Although S7 returns into the field all WW straw and does not have an economic benefit from its sale, and despite having a considerable reduction in WW grain and potatoes in comparison with its alternative scenarios (S1 and S4), it is compensated by the highest market price for the organic grain and organic tuber $(0.48$ $€ \cdot \mathrm{kg}^{-1}$ and $0.28 € \cdot \mathrm{kg}^{-1}$, respectively) as well as with the lowest costs (see Table 1 ).

Conversely, although Galician WW under conventional management (S4-S6) reports lower yields than its commercial counterpart (ca. 50\%), the higher market price for the grain $\left(0.40 € \cdot \mathrm{kg}^{-1} \mathrm{vs} 0.20 € \cdot \mathrm{kg}^{-1}\right)$ together with the lowest costs associated to the cultivation (mainly those related to the inputs) helps get higher gross margins and accordingly, better environmental profiles for the scenarios including the native variety.

The environmental results show that the organic scenarios including maize and oilseed rape (S8 and S9) report low environmental burdens in practically all impact categories when the profiles are analysed per $€$ of revenue. These cropping systems produce lower amounts of WW grain and co-products than the conventional ones, although the highest prices for the organic products maintain the revenue.

These findings highlight the importance of the selection of an appropriate unit due to the high productivity of the more intensive systems (i.e., conventional regimes) and the highest market prices for organic products. Thus, the impact on the environment from conventional regimes may be more penalized when considering a unit based on the economic revenue.

\subsection{Preference ranking of crop rotation systems}

An environmental comparison between the nine crop rotation systems based on an endpoint method has been performed to have a single environmental score per scenario (adimensional) and establish a ranking or classification from the most to the least environmental-friendly system. This procedure could facilitate easier communication of results giving a dimensionless single indicator (so-called single score). Single or normalized scores are -regardless of the fact that weighted results are not recommended for public dissemination by the International Organization for Standardization (ISO, 2006b) - becoming more popular, at least for comparative assessments (Kalbar et al., 2016). The normalization step transforms results expressed at different scales to a common one, pursuing a specific purpose (among others) that is to compare the result with a reference quantity, checking its consistency and facilitate its communication. Nevertheless, discrepancies also exist among scientific community regarding the use of normalization factors, since they can increase uncertainty in the results (Hélias et al., 2020).

For this purpose, the normalization factors taken from ReCiPe 2016 Mindpoint method (hierarchist version with a 100-year time horizon) have been applied (Huijbregts et al., 2016). The analysis at normalization level reports the results in a single number that allows the direct comparison between equivalent systems. The normalized values are detailed in Table 3. S9 can be considered the best crop rotation when the results are reported per ha. This scenario including OSR and Ge-WW reports the lowest environmental normalized score. In addition, all ecological scenarios occupy the top-three positions being the preferred cultivation option in terms of land use despite having lowest yields. Conversely, S1 and S4 (both including potato as alternate crop with wheat) are the least environmentally friendly crop rotation systems per ha. Bearing in mind the previous discussion, the cultivation of potato is quite intensive in terms of agricultural operations and thus, it demands large amounts of diesel and agrochemicals with the corresponding environmental burdens.

If the analysis is performed per $€$ of gross margin, the ecological scenarios (S7-S9) are once again the ones with the lowest environmental

Table 2

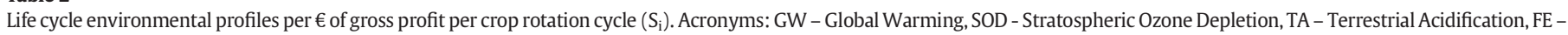
Freshwater Eutrophication, ME - Marine Eutrophication, TET - Terrestrial Ecotoxicity, MET - Marine Ecotoxicity, FRS - Fossil Resource Scarcity.

\begin{tabular}{|c|c|c|c|c|c|c|c|c|c|c|}
\hline Impact category & Unit & $\mathrm{S} 1$ & $\mathrm{~S} 2$ & S3 & $\mathrm{S} 4$ & S5 & S6 & S7 & S8 & S9 \\
\hline GW & $\mathrm{kgCO}_{2} \mathrm{eq}$ & 6.83 & 28.99 & 106.6 & 1.52 & 2.93 & 0.80 & 1.09 & 1.80 & 1.45 \\
\hline SOD & g CFC11eq & 0.130 & 0.748 & 4.25 & 0.036 & 0.092 & 0.072 & 0.028 & 0.055 & 0.075 \\
\hline TA & $\mathrm{g} \mathrm{SO}_{2} \mathrm{eq}$ & 50.59 & 246.4 & 1272 & 13.09 & 27.86 & 17.98 & 43.98 & 70.95 & 102.9 \\
\hline $\mathrm{FE}$ & g Peq & 2.80 & 13.52 & 76.30 & 0.790 & 1.64 & 1.26 & 0.751 & 0.787 & 1.24 \\
\hline ME & $\mathrm{g} \mathrm{Neq}$ & 18.92 & 53.72 & 391.6 & 6.31 & 6.81 & 7.30 & 9.57 & 6.79 & 14.68 \\
\hline TET & kg 1,4-DCB & 39.01 & 114.0 & 578.0 & 12.20 & 13.44 & 8.74 & 3.59 & 4.08 & 6.40 \\
\hline FET & kg 1,4-DCB & 0.288 & 1.36 & 4.80 & 0.087 & 0.173 & 0.072 & 0.030 & 0.020 & 0.032 \\
\hline MET & kg 1,4-DCB & 0.495 & 2.18 & 6.39 & 0.159 & 0.285 & 0.098 & 0.040 & 0.028 & 0.045 \\
\hline FRS & kg oil eq & 1.10 & 5.26 & 27.12 & 0.312 & 0.64 & 0.437 & 0.230 & 0.226 & 0.341 \\
\hline
\end{tabular}


Table 3

Environmental normalized score for each rotation cycle $\left(\mathrm{S}_{\mathrm{i}}\right)$. In black, the least preferred option is highlighted and in grey, the most.

\begin{tabular}{c|c|c|c|c|c|c|c|c|c} 
& S1 & S2 & S3 & S4 & S5 & S6 & S7 & S8 & S9 \\
\hline Environmental score per ha & 12,166 & 7901 & 4994 & 10,094 & 6347 & 3440 & 2357 & 2713 & 2199 \\
\hline Gross margin (€) per ha & 2524 & 554 & 70 & 6698 & 3766 & 3176 & 5274 & 5363 & 2771 \\
\hline Environmental score per $€$ & 4.82 & 14.26 & 71.59 & 1.51 & 1.69 & 1.08 & 0.447 & 0.506 & 0.794 \\
\hline Environmental score rank per & 9 & 7 & 5 & 8 & 6 & 4 & 2 & 3 & 1 \\
ha & 7 & 8 & 9 & 1 & 4 & 5 & 3 & 2 & 6 \\
\hline Environmental score rank per & 7 & 8 & 9 & 5 & 6 & 4 & 1 & 2 & 3
\end{tabular}

scores being, in this case, $\mathrm{S} 7$ the preferred one. This scenario includes $\mathrm{P}$ and Ge-WW and it is one of the cycled rotations with the highest gross margin. The cropping systems including the commercial WW variety (S1-S3) are those with the highest environmental scores and S3 occupies the worst preferred position to cultivate WW. The rationale behind this finding is directly related with the gross margin, which is really low (only $70 €$ per ha) in comparison with the alternative scenarios under study. In this sense, in terms of economic benefits (gross margin rank), the preferred cultivation scenarios are those including the native WW variety. In first place when it is cultivated under conventional management in a rotation with potato (S4) because of the high revenues from the sales of co-products. Then, the preferred scenarios should include native WW under rotation with maize (S8) and potato (S7) with gross margins of around $5300 €$ on average. The rationale behind their positions is linked to the low costs of cultivation in S8 and high revenue in S7. Having in mind these results, discrepancies arise regarding the preference ranking depending on the considered unit to report the results and thus, on the audience to which the message is intended.

\section{Comparison with other studies, improvement strategies and conclusions}

It is difficult to make a direct comparison with other studies available in the literature focused on crop rotation systems considering the winter wheat varieties have not been previously analysed. Therefore, the comparison will focus on the main findings and differences with other studies. Herbaceous crops and the specialization of cereal-based cropping systems have a significant impact on numerous environmental categories, especially due to the use of fertilizers (organic or inorganic) and mechanical operations focused on soil establishment and crop maintenance. Although the contribution of different processes to the overall profiles may differ among studies, $\mathrm{N}$ fertilization is always ranked as the main environmental hotspot not only in terms of $\mathrm{N}$ derived emissions that play a key role in categories such as $\mathrm{GW}\left(\mathrm{N}_{2} \mathrm{O}\right.$ emission), $\mathrm{FE}$ (nitrate emission) and $\mathrm{TA}\left(\mathrm{NH}_{3}\right.$ and $\mathrm{N}_{2} \mathrm{O}$ emissions) but also in terms of energy requirements associated with the background processes involved in the production of mineral fertilizers, which affects categories such as GW, TA and FRS. This issue was highlighted in numerous studies, such as Nemecek et al. (2015), Ankathi et al. (2019), Goglio et al. (2012) and Hayer et al. (2009), where different alternative croprotation systems were environmentally assessed. Guardia et al. (2016) suggested that crop rotation with legumes could be a desirable strategy in Spain to reduce $\mathrm{N}$-fertilizers dependence, interrupt disease and pest cycles and reduce environmental consequences. Legume crops do not require synthetic nitrogen fertilization because they establish a symbiosis with Rhizobium bacteria present in the soil to fix atmospheric nitrogen (Nemecek et al., 2008). It is also beneficial for soil quality. According to Plaza-Bonilla et al. (2017), it is possible to maintain cereal yields and grain quality in specialized systems by reducing the application of $\mathrm{N}$ fertilizers with the incorporation of grain legumes in the rotation cycle. Thus, the application of nitrogen fertilizers could be considerably reduced in the crops that follow the leguminous plants, which would lead to considerable environmental improvements (reduction of field emissions, such as $\mathrm{N}_{2} \mathrm{O}$ and nitrate leaching, among others, as well as less use of machinery). Therefore, the incorporation of legume crops in specialized cereal-based cropping systems can be considered as a potential alternative since the legumes meet the $\mathrm{N}$ requirements of the subsequent crop.

However, best crop-management practices (e.g. $\mathrm{N}$ fertilization rates and timing, soil management and weeding) should be applied since legume straw is rich in nitrogen, which may be lost through emissions to water (e.g., nitrate leaching) and air $\left(\mathrm{N}_{2} \mathrm{O}\right)$ (Nemecek et al., 2008; PlazaBonilla et al., 2017). In this regard, nitrate leaching could be reduced by including catch crops (rye, oat, and sunflower) or sowing winter grain legumes (faba bean and pea), where possible (Nemecek et al., 2008; Neugschwandtner et al., 2019).

Other agrochemicals, such as pesticides, insecticides and fungicides, which are required in conventional management (and with high intensity in some crops such as potato and maize) show a significant contribution to the toxicity-related categories due to the field emissions derived from their application. In contrast, the effect of their production is negligible in the global profiles. This finding is not consistent with the results of other studies. On the one hand, because in those studies the dosage of agrochemicals applied is considerably lower than in our crops. On the other hand, field emissions are not always considered null or negligible (Goglio et al., 2012).

Crop operations, i.e., activities in the field that require diesel and involve tailpipe emissions, were identified in crop systems as critical contributors to the environmental profile by numerous studies (Jeswani et al., 2018; Hayer et al., 2009). In our results, the effect from agricultural activities is relevant but not so remarkable because of fertilization. Nevertheless, these operations play a key role in FRS.

The sensitivity of the results to the delimitation of the system boundaries can be demonstrated according to the results identified. Avoided mineral fertilization processes, carbon storage in the soil when returning straw to the field, as well as electricity production in ecological systems, clearly influence the environmental profiles.

Bearing in mind the main findings, LCA tool is an excellent candidate for helping the selection of policy interventions towards more environmentally sustainable agricultural systems. Policy challenges would include reducing environmental impacts associated with 
mineral fertilization and optimising the systems by means of the benefits from rotation regimes.

\section{Availability of data and materials}

All data generated or analysed during this study are included in this published article.

\section{Ethical approval}

Not applicable.

\section{CRediT authorship contribution statement}

Sara González-García and Miguel Brandão contributed to the study conception and design. Material preparation and data collection were performed by Sara González-García and Fernando Almeida. Data analysis, conceptualization, investigation, and methodology were performed by Sara González-García and Miguel Brandão. The first draft of the manuscript was written by Sara González-García. Miguel Brandão performed a detailed supervision of the study. All authors commented on previous versions of the manuscript. All authors read and approved the final manuscript.

\section{Declaration of competing interest}

The authors declare that they have no known competing financial interests or personal relationships that could have appeared to influence the work reported in this paper.

\section{Acknowledgments}

This research has been supported by the project Enhancing diversity in Mediterranean cereal farming systems (CerealMed) project funded by PRIMA Programme and FEDER/Ministry of Science and Innovation - Spanish National Research Agency (PCI2020-111978), by FEDER 2019/058A project in collaboration with Panaderia da Cunha and by a project granted by Xunta de Galicia (project ref. ED431F 2016/001). S.G.-G. and M.T.M. belong to the Galician Competitive Research Group GRC2013-032, co-funded by Xunta de Galicia and FEDER (EU). S.G-G. would like to express her gratitude to the Spanish Ministry of Economy and Competitiveness (Grant references RYC-2014-14984) and the Spanish Ministry of Education and Professional Training (Grant reference CAS19/00037) for financial support.

\section{Appendix A. Supplementary data}

Supplementary data to this article can be found online at https://doi. org/10.1016/j.scitotenv.2021.145270.

\section{References}

Ankathi, S.K., Long, D.S., Gollany, H.T., Das, P., Shonnard, D., 2019. Life cycle assessment of oilseed crops produced in rotation with dryland cereals in the inland Pacific Northwest. The International Journal of Life Cycle Assessment 24, 627-641.

Bhardwaj, A.K., Jasrotia, P., Hamilton, S.K., Robertson, G.C., 2011. Ecological management of intensively cropped agro-ecosystems improves soil quality with sustained productivity. Agriculture, Ecosystems and Environment 140, 419-429.

Blandino, M., Visioli, G., Marando, S., Marti, A., Reyneri, A., 2020. Impact of late-season N fertilisation strategies on the gluten content and composition of high protein wheat grown under humid Mediterranean conditions. Journal of Cereal Science 94, 102995.

Brandão, M., 2012. Food, Feed, Fuel, Timber or Carbon Sink? Towards Sustainable Landuse Systems - A Consequential Life Cycle Approach. Centre for Environmental Strategy. Faculty of Engineering and Physical Sciences. University of Surrey, UK, p. 241 (PhD thesis).

Câmara-Salim, I., Almeida-García, F., González-García, S., Romero-Rodríguez, A., RuízNogueiras, B., Pereira-Lorenzo, S., Feijoo, G., Moreira, M.T., 2020. Life cycle assessment of autochthonous varieties of wheat and artisanal bread production in Galicia, Spain. Science of the Total Environment 713, 136720.
Campo de Tejada, 2020. https://www.campodetejada.es/en/products/cereals/commonwheat/ (accessed July 2020).

Cortés, A., Feijoo, G., Fernández, M., Moreira, M.T., 2021. Pursuing the route to ecoefficiency in dairy production: The case of Galician area. J. Clean. Prod. 285, 124861.

Deytieux, V., Nemecek, T., Knuchel, R.F., Gaillard, G., Munier-Jolain, N.M., 2012. Is integrated weed management efficient for reducing environmental impacts of cropping systems? A case study based on life cycle assessment. European Journal of Agronomy 36, 55-65.

EEA - European Environment Agency, 2019. EMEP/EEA air pollutant emission inventory guidebook 2019. Nicholas Hutchings, J. Webb, Barbara Amon Guidebook 2019.

Ekvall, T., 2020. Attributional and consequential life cycle assessment. Chapter 4. In: Bastante-Ceca, María José, Fuentes-Bargues, Jose Luis, Hufnagel, Levente, Mihai, FlorinConstantin, Iatu, Corneliu (Eds.), Sustainability Assessment at the 21st Century. IntechOpen, London (UK). ISBN: 978-1-78984-977-6.

Erice, G., Sanz-Sáez, Á., González-Torralba, J., Méndez-Espinoza, A.M., Urratavizcaya, I., Nieto, M.T., Serret, M.D., Araus, J.L., Irigoyen, J.J., Aranjuelo, I., 2019. Impact of elevated $\mathrm{CO} 2$ and drought on yield and quality traits of a historical (Blanqueta) and a modern (Sula) durum wheat. Journal of Cereal Science 87, 194-201.

Eurostat, 2020. https://ec.europa.eu/eurostat/statistics-explained/index.php/Agricultural_production_-_crops (accessed July 2020).

Faist Emmenegger, M., Reinhard, J., Zah, R., 2009. Sustainability Quick Check for Biofuels Intermediate Background Report. With Contributions From T. Ziep, R. Weichbrodt Prof. Dr. V. Wohlgemuth, FHTW Berlin and A. Roches, R. Freiermuth Knuchel, Dr. G. Gaillard. Agroscope Reckenholz-Tänikon, Dübendorf, Switzerland.

Fang, Y., Singh, B.P., Cowie, A., Wang, W., Arachchi, M.H., Wang, H., Tavakkoli, E., 2019. Balancing nutrient stoichiometry facilitates the fate of wheat residue-carbon in physically defined soil organic matter fractions. Geoderma 354, 113883.

Ghaley, B.B., Rusu, T., Sandén, T., Spiegel, H., Menta, C., Visioli, G., et al., 2018. Assessment of benefits of conservation agriculture on soil functions in arable production systems in Europe. Sustainability 10 (3), 794

Goglio, P., Bonari, E., Mazzoncini, M., 2012. LCA of cropping systems with different external input levels for energetic purposes. Biomass \& Bioenergy 42, 33-42.

González-García, S., Bacenetti, J., Negri, M., Fiala, M., Arroja, L., 2013. Comparative environmental performance of three different annual energy crops for biogas production in Northern Italy. Journal of Cleaner Production 43, 71-83.

Gonzalez-Garcia, S., Gomez-Fernandez, Z., Dias, A.C., Feijoo, G., Moreira, M.T., Arroja, L., 2014. Life Cycle Assessment of broiler chicken production: a Portuguese case study. J. Clean. Prod. 74, 125-135.

González-García, S., Baucells, F., Feijoo, G., Moreira, M.T., 2016. Environmental performance of sorghum, barley and oat silage production for livestock feed using life cycle assessment. Resources Conservation \& Recycling 111, 28-41.

Guardia, G., Tellez-Rio, A., García-Marco, S., Martin-Lammerding, D., Tenorio, J.L., Ibáñez, M.A., Vallejo, A., 2016. Effect of tillage and crop (cereal versus legume) on greenhouse gas emissions and global warming potential in a non-irrigated Mediterranean field. Agriculture, Ecosystems and Environment 221, 187-197.

Habermeyer, M., Roth, A., Guth, S., Diel, P., Engel, K.H., et al., 2015. Nitrate and nitrite in the diet: how to assess their benefits and risk for human health. Molecular Nutrition \& Food Research 59, 106-128

Hayer, F., Bonnin, E., Carrouée, B., Gaillard, G., Nemecek, T., Schneider, A., Vivier, C., 2009. Designing sustainable crop rotations using life cycle assessment of crop combinations. 9th European IFSA Symposium, 4-7 July 2009, Vienna (Austria).

Hélias, A., Esnouf, A., Finkbeiner, M., 2020. Consistent normalization approach for life cycle assessment based on inventory databases. Science of the Total Environment 703, 134583.

Hellemans, T., Landschoot, S., Dewitte, K., Van Bockstaele, F., Vermeir, P., Eeckhout, M., Haesaert, G., 2018. Impact of crop husbandry practices and environmental conditions on wheat composition and quality: a review. Journal of Agricultural Food Chemistry $66,2491-2509$.

Hendrickson, J., Colazo, J.C., 2019. Chapter 6 - using crop diversity and conservation cropping to develop more sustainable arable cropping systems. Agroecosystem Diversity Reconciling Contemporary Agriculture and Environmental Quality, pp. 93-108.

Huijbregts, M.A.J., Steinmann, Z.J.N., Elshout, P.M.F., Stam, G., Verones, F., Vieira, M., Zijp, M., Hollander, A., van Zelm, R., 2016. ReCiPe2016. A harmonized life cycle impact assessment method at midpoint and endpoint level. Report I: Characterization. RIVM Report 2016-0104. National Institute for Human Health and the Environment, Bilthoven.

Huijbregts, M., Steinmann, Z.J.N., Elshout, P.M.F., et al., 2017. ReCiPe2016: a harmonised life cycle impact assessment method at midpoint and endpoint level. The International Journal of Life Cycle Assessment 22, 138-147.

IPCC - The Intergovernmental Panel on Climate Change, 2019. $\mathrm{N}_{2} \mathrm{O}$ emissions from managed soils, and $\mathrm{CO}_{2}$ emissions from lime and urea application chapter 11. $2019 \mathrm{Re}-$ finement to the 2006 IPCC Guidelines for National Greenhouse Gas Inventories. Volume 4. Agriculture, Forestry and Other Land Use.

ISO, 2006a. ISO 14040 Environmental Management - Life Cycle Assessment - Principles and Framework (Geneva).

ISO, 2006b. ISO 14044- Environmental Management - Life Cycle Assessment Requirements and Guidelines (Geneva).

Jeswani, H.K., Espinoza-Orias, N., Crocker, T., Azapagic, A., 2018. Life cycle greenhouse gas emissions from integrated organic farming: a systems approach considering rotation cycles. Sustainable Production and Consumption 13, 60-79.

Jin, Z., Shah, T., Zhang, L., Liu, H., Peng, S., Nie, L., 2020. Effect of straw returning on soil organic carbon in rice-wheat rotation system: A review. Food Energy Secur. 9, e200. https://doi.org/10.1002/fes3.200.

Kalbar, P.P., Birkved, M., Nygaard, S.E., Hauschild, M., 2016. Weighting and aggregation in life cycle assessment. Do present aggregated single scores provide correct decision support? Journal of Industrial Ecology 21 (6), 1591-1600. 
Le Gouis, J., Oury, F.X., Charmet, G., 2020. How changes in climate and agricultural practices influenced wheat production in Western Europe. Journal of Cereal Science 93, 102960.

Li, G., Zakari, A., Tawiah, V., 2020. Does environmental diplomacy reduce $\mathrm{CO}_{2}$ emissions? A panel group means analysis. Science of the Total Environment 722, 137790.

Liu, Q., Q., N., Xu, X., Xin, X., Han, J.Y., Tian, Y., Ouyang, H., Kuzyakov, Y., 2016. Nitrogen acquisition by plants and microorganisms in a temperate grassland. Scientific Reports 6 , 22642.

Mäkinen, H., Kaseva, J., Trnka, M., Balek, J., Kersebaum, K.C., Nendel, C., Gobin, A., et al., 2018. Sensitivity of European wheat to extreme weather. Field Crops Research 222, 209-217.

Nemecek, T., von Richthofen, J.-S., Dubois, G., Casta, P., Charles, R., Pahl, H., 2008. Environmental impacts of introducing grain legumes into European crop rotations. European Journal of Agronomy 28, 380-393.

Nemecek, T., Huguenin, O., Dubois, D., Gaillard, G., 2011a. Life cycle assessment of Swiss farming systems: I. Integrated and organic farming. Agricultural Systems 104, 217-232.

Nemecek, T., Huguenin, O., Dubois, D., Gaillard, G., Schaller, B., Chervet, A., 2011b. Life cycle assessment of Swiss farming systems: II. Extensive and intensive production. Agricultural Systems 104, 233-245.

Nemecek, T., Hayer, F., Bonnin, E., Carrouée, B., Schneider, A., Vivier, C., 2015. Designing eco-efficient crop rotations using life cycle assessment of crop combinations. European Journal of Agronomy 65, 40-51.

Neugschwandtner, R.W., Bernhuber, A., Kammlander, S., Wagentristl, H., Klimek-Kopyra, A., Kaul, H.P., 2019. Agronomic potential of winter grain legumes for Central Europe: development, soil coverage and yields. Field Crops Research 241, 107576.

Noya, I., González-García, S., Bacenetti, J., Arroja, L., Moreira, M.T., 2015. Comparative life cycle assessment of three representative feed cereals production in the Po Valley (Italy). Journal of Cleaner Production 99, 250-265.

Noya, I., González-García, S., Bacenetti, J., Fiala, M., Moreira, M.T., 2017. Environmental impacts of the cultivation-phase associated with agricultural crops for feed production. Journal of Cleaner Production 172, 3721-3733.

Oteros, J., García-Mozo, H., Botey, R., Mestre, A., Galán, C., 2015. Variations in cereal crop phenology in Spain over the last twenty-six years (1986-2012). Climatic Change 130, 545-558.
Pan, B., 2016. Ammonia volatilization from synthetic fertilizers and its mitigation strategies: a global synthesis. Agricultutal, Ecosystems and Environment 232, 283-289.

PEFCR guidance, 2017. https://ec.europa.eu/environment/eussd/smgp/pdf/PEFCR_guidance_v6.3.pdf (accessed July 2020).

Pishgar-Komleh, S., Sefeedpari, P., Pelletier, N., Brandão, M., 2019. Life cycle assessment methodology for agriculture: some considerations for best practices. Assessing the Environmental Impact of Agriculture. Burleigh Dodds Science Publishing Limited, pp. 229-257.

Plaza-Bonilla, D., Nolot, J.-M., Raffaillac, D., Justes, E., 2017. Innovative cropping systems to reduce $\mathrm{N}$ inputs and maintain wheat yields by inserting grain legumes and cover crops in southwestern France. Eur. J. Agron. 82, 331-341.

Prasuhn, V., 2006. Erfassung der PO4-Austräge für die Ökobilanzierung - SALCAPhosphor. Agroscope FAL Reckenholz, Zürich 22 p., Available at. www.agroscope. admin.ch.

PRé Consultants, 2020. SimaPro Database Manual. Methods library, The Netherlands.

SAAFFM - Food and Fishing Ministry, 2018. Statistical Annuary of Agriculture. SAAFFM, Madrid https://www.mapa.gob.es/estadistica/pags/anuario/2019-Avance/avance/ AvAE19.pdf.

Salim, I., González-García, S., Feijoo, G., Moreira, M.T., 2019. Assessing the environmental sustainability of glucose from wheat as a fermentation feedstock. Journal of Environmental Management 247, 323-332.

Schmidt, J.H., Weidema, B.P., Brandão, M., 2015. A framework for modelling indirect land use changes in life cycle assessment. Journal of Cleaner Production 99, 230-238.

Watts-Williams, S., Cavagnaro, T., 2018. Arbuscular mycorrhizal fungi increase grain zinc concentration and modify the expression of root ZIP transporter genes in a modern barley (Hordeum vulgare) cultivar. Plant Science 274

Wernet, G., Bauer, C., Steubing, B., Reinhard, J., Moreno-Ruiz, E., Weidema, B., 2016. The ecoinvent database version 3 (part I): overview and methodology. The International Journal of Life Cycle Assessessment 21, 1218-1230.

Wowra, K., Zeller, V., Schebek, L., 2020. Nitrogen in Life Cycle Assessment (LCA) of agricultural crop production systems: Comparative analysis of regionalization approaches. Science of the Total Environment https://doi.org/10.1016/j.scitotenv.2020.143009 (In press).

Xynias, Y.N., Mylonas, I., Korpetis, E.G., Ninou, E., Tsaballa, A., Avdikos, I.D., Mavromatis, A.G., 2020. Durum wheat breeding in the mediterranean region: current status and future prospects. Agronomy 10, 432 